\title{
Review \\ The Relationship between Mucins and Ulcerative Colitis: A Systematic Review
}

\author{
Esther Bankole, Emily Read, Michael A. Curtis, Joana F. Neves (D) and James A. Garnett *(D) \\ Centre for Host-Microbiome Interactions, Faculty of Dentistry, Oral \& Craniofacial Science, King's College \\ London, London SE1 9RT, UK; esther.bankole18@imperial.ac.uk (E.B.); emily.read@kcl.ac.uk (E.R.); \\ mike.curtis@kcl.ac.uk (M.A.C.); joana.pereira_das_neves@kcl.ac.uk (J.F.N.) \\ * Correspondence: james.garnett@kcl.ac.uk
}

Citation: Bankole, E.; Read, E.; Curtis, M.A.; Neves, J.F.; Garnett, J.A. The Relationship between Mucins and Ulcerative Colitis: A Systematic Review. J. Clin. Med. 2021, 10, 1935. https://doi.org/10.3390/jcm10091935

Academic Editor: Mariangela Allocca

Received: 14 April 2021

Accepted: 27 April 2021

Published: 30 April 2021

Publisher's Note: MDPI stays neutral with regard to jurisdictional claims in published maps and institutional affiliations.

Copyright: (C) 2021 by the authors. Licensee MDPI, Basel, Switzerland. This article is an open access article distributed under the terms and conditions of the Creative Commons Attribution (CC BY) license (https:/ / creativecommons.org/licenses/by/ $4.0 /)$.

\begin{abstract}
Mucins are a family of glycosylated proteins which are the primary constituents of mucus and play a dynamic role in the regulation of the protective mucosal barriers throughout the human body. Ulcerative colitis (UC) is an Inflammatory Bowel Disease (IBD) characterised by continuous inflammation of the inner layer of the large intestine, and in this systematic review we analyse currently available data to determine whether alterations exist in mucin activity in the colonic mucosa of UC patients. Database searches were conducted to identify studies published between 1990 and 2020 that assess the role of mucins in cohorts of UC patients, where biopsy specimens were resected for analysis and control groups were included for comparison. 5497 articles were initially identified and of these 14 studies were systematically selected for analysis, a further 2 articles were identified through citation chaining. Therefore, 16 studies were critically reviewed. 13 of these studies assessed the role of MUC2 in UC and the majority of articles indicated that alterations in MUC2 structure or synthesis had an impact on the colonic mucosa, although conflicting results were presented regarding MUC2 expression. This review highlights the importance of further research to enhance our understanding of mucin regulation in UC and summarises data that may inform future studies.
\end{abstract}

Keywords: mucin; MUC; ulcerative colitis; Inflammatory Bowel Disease; mucosa; intestine

\section{Introduction}

Mucin (MUC) genes encode a family of glycosylated proteins-mucins, which constitute the primary organic component of mucus [1]. The biophysical and biochemical properties of mucus are governed by mucin structure. Mucus is present on the surface of mucosal epithelial cells [1] and the role of mucus and the mucosal epithelia in health and disease is dynamic. Mucosal surfaces act as the first line of defense against pathogenic microbes and foreign particles [2]. In addition to forming a physical barrier which prevents the entry of pathogens into mucosal epithelia, mucus, synthesised by goblet cells, is a lubricant which protects the epithelia from damage and retains cellular hydration $[2,3]$. Mucins are essential components of mucus and the mucosal defense system, regulating the absorption of nutrients and offering protection against infections that may lead to mucosal disease $[1,4,5]$. Currently the expression of 21 MUC genes (mRNA and/or protein) have been identified at various mucosal sites throughout the body [6].

Mucins are characterised by their central domain, which is composed of a protein backbone containing Proline, Threonine and Serine (PTS) rich Variable Number Tandem Repeat (VNTR) sequences, also termed tandemly repeated polypeptides. The PTS rich tandemly repeated polypeptides have extensive $O$-linked glycans $[4,7,8]$. O-linked glycans are attached within the PTS rich regions as glycosidic bonds between the side chain hydroxyl groups of serine and threonine residues and the sugar $N$-acetylgalactosamine (GalNAc) [2,3]. N-linked glycans on the other hand tend to be found towards the terminal domains of mucins $[4,9]$. 
The length and number of PTS rich VNTRs can be used to distinguish mucins from each other $[4,5,10]$. For example, structural analysis of MUC1 has revealed an uninterrupted PTS region whilst MUC2 has two PTS-regions [10]. Differences in the structures of mucins, particularly in the assembly of their domains are reflective of their functions, which are dependent on the location of the mucosal epithelia from which they originate within the body [2]. For this reason, mucins can be described as tissue specific molecules $[2,5,10]$. There are two major groups of mucins: secretory mucins and membrane-associated mucins $[9,11,12]$. Secretory mucins can be divided into the subgroups secreted soluble mucins (or non-gel forming) and secreted gel forming mucins. Mucins within the same group share distinctive conserved domains.

Membrane-associated mucins such as MUC1 have a monomeric structure and contain distinct transmembrane domains, which enable them to be incorporated into the apical cell surface of epithelia, as well as a short cytoplasmic tail and a Sea urchin-EnterokinaseAgrin (SEA) domain $[2,4,13]$. The SEA domain joins the tandemly repeated polypeptide region to the transmembrane domain. Some of the membrane-associated mucins also have an Epidermal-Growth-Factor (EGF) like domain [10,14]. Instead of the SEA domain, MUC4 has a Nidogen-AMOP domain [10,15]. Secreted gel forming mucins such as MUC2 have an oligomeric structure which appears as a layered network of monomers bonded together through disulphide bridges whereas secreted soluble mucins such as MUC7 are much smaller and appear monomeric $[2,10,16]$. The gel forming secreted mucins can be distinguished by their cysteine rich domains and their ability to form von Willebrand factor like C and D domains $[4,10,17]$. However, the secreted soluble mucins (MUC7, MUC8, MUC9) are not as well characterised as secreted gel forming mucins.

In order for the mucosal barrier to maintain protection against external pathogens, mucins are required to take part in various pathways [2]. Mucin degradation and turnover are essential processes that help to balance the equilibrium between the biosynthesis of mucosal membranes and the secretion and breakdown of mucus gel, which in turn regulates the protective mucosal barrier [2]. To understand the significance of mucin degradation and to explore how degradation occurs, the structure of mucins and their ability to form interactions with microbes must be understood [2,3]. It has been shown that mucins have a dualistic role within the protective barrier; mucins are able to prevent the entry of pathogenic organisms/substances by adhering to them whilst also forming interactions with commensal bacteria via glycosylated attachment sites $[3,18,19]$. It must be noted that by forming these interactions with bacteria, mucins provide an energy source for bacteria capable of mucin degradation [2,3]. Binding of mucins to bacteria thereby facilitates their breakdown by mucin degrading enzymes that cleave glycosidic bonds; thus, it can be said that mucins also act as substrates for mucin degrading bacteria [2,3]. Although mucin degradation is essential, in some cases, the equilibrium between mucin degradation and mucosal biosynthesis becomes perturbed leading to a shift in the composition of the microbiota [2,3]. In these circumstances, mucin degradation may be associated with the primary stages of the development of mucosal diseases, such as Inflammatory Bowel Disease (IBD).

IBD is a term used to describe diseases characterised by chronic intestinal inflammation such as Crohn's Disease (CD) and Ulcerative Colitis (UC) [20,21]. Several differences exist between $C D$ and $U C$, including the distribution and spread of inflammation. In $\mathrm{UC}$, inflammation is continuous, uniform and is restricted to the superficial layers of the large intestine [20]. In contrast, in CD inflammation is observed in any region of the gastrointestinal tract (GI tract) from the mouth to the anus, is discontinuous and occurs in all of the layers lining the intestines [20,22]. The global burden and incidence of IBD continues to rise, with more than 6.8 million cases of IBD worldwide reported in 2017 [23]. The underlying aetiology of IBD remains unclear. IBD is multifactorial; the incidence of IBD can be associated with immune disorders, genetics, environment and interactions with microbes [20]. Recent research has suggested that perturbation and dysfunction of the intestinal mucosal membrane is related to the pathogenesis of IBD [3]. 
Analysis of biopsy samples of the colonic mucus lining shows the presence of two sub-layers: an outer layer that acts as a lubricant and an inner or adherent layer that acts as a selective barrier. This adherent layer limits direct contact between the luminal contents (including the microbiota) and epithelial cells and is the site of expression for the majority of mucins detected in the colon $[3,24]$. MUC2 is the most prominently expressed mucin in the colon of both healthy individuals and individuals with UC [3,25]. However, biopsy samples have revealed that the adherent mucus layer of patients with UC is thinner, particularly in areas of inflammation [26] As described above, goblet cells are responsible for the synthesis and excretion of mucins such as MUC2 [25] and it has been suggested that the reduction of goblet cells associated with UC mucosal perturbation is related to a reduction in the expression of mucins. This is associated with a loss of integrity of the mucosal barrier, which leads to infiltration of microbes into the mucosa, increasing the contact between the epithelia and microbiota, which promotes further inflammation [24]. However, the significance of aberrant mucin expression in UC remains uncertain.

This review aims to compile recent data regarding the relationship between mucin activity and UC, in order to provide a clear, concise summary which can be used to inform further studies in this area of research. In addition, the collated information is used to identify any possible correlations between mucin expression levels and mucin degradation within the colon of UC patients. An improved understanding of the role that mucins and their turnover play in the protective barrier at mucosal membranes will be important in clarifying their potential involvement in the prevention of mucosal disease such as UC and CD.

\section{Materials and Methods}

\subsection{Review Questions}

1. Does mucin expression and activity change in patients with UC compared to healthy controls?

2. How do changes in mucin expression effect mucus structure?

3. What impact do these changes have on host-microbiome interactions and inflammation?

\subsection{Search Strategy}

An electronic search was performed in the following databases up until December 2020: PubMed, Ovid MEDLINE, Cochrane CENTRAL (TRIALS) and Web of Science. The search terms used to address the objectives were:

- Colitis AND mucin *

- (IBD OR Inflammatory Bowel Disease) AND mucin *

- (IBD OR Inflammatory Bowel Disease) AND mucin * degradation To optimise the retrieval of articles in databases, Boolean operators were used (AND, OR). Using 'AND' allows for citations containing all search terms to be retrieved, whereas using 'OR' can produce citations containing at least one of a group of search terms. Therefore, 'OR' was used here where words were similar/related e.g. IBD and Inflammatory Bowel Disease. Mucin was also truncated (truncation is indicated by Asterix - *) in order to find citations including mucin and all words with the stem 'mucin' e.g. mucin, mucins, mucinase.

\subsection{Study Selection and Items Collected}

To aid with the screening process, articles found during the search process were imported from databases to Covidence (Veritas Health Innovation, Australia), the Cochrane approved systematic review manager. Duplicates were identified and removed automatically using Covidence and the remaining articles were moved to a panel for screening. Titles and abstracts were screened to determine whether articles matched the study criteria. Articles that matched study criteria were moved to another panel for full text screening and in accordance with the inclusion criteria, eligible studies were chosen to be included for subsequent analysis and data extraction. The inclusion and exclusion criteria were entered 
into the Covidence programme, so as papers were excluded the reasons for exclusion were recorded for each paper. Following inclusion of relevant articles, citation chaining was carried out. Forwards citation chaining (to identify articles that cited an included paper and that were also relevant to the systematic review search questions) was carried out for each included article by searching article titles in Google Scholar and using the 'cited by' feature of the Google Scholar search. Backwards citation (to identify articles that an included paper cited and that were also relevant to the systematic review search questions) was carried out for each included article by manually scanning the references listed in included articles. Additional articles identified through citation chaining were imported directly into the data extraction panel in Covidence. Data were extracted from studies using the data extraction tool within Covidence, extracted data was summarised based on identification (Author, Country), methods used (study design, experiments/investigations), population (study size, study groups included), outcomes (key findings, conclusion from study).

\subsection{Inclusion E Exclusion Criteria}

The inclusion criteria were articles where mucin mRNA and/or mucin protein expression had been studied and recorded in a cohort of patients with colitis/healthy controls; articles which assessed mucin structural changes in patients with colitis; articles which investigated mucin expression in reference to inflammation, disease severity and maintenance of the colonic mucosal epithelia; and articles published between 1990 and 2020. Review papers and meta-analysis reports, conference abstracts, doctoral theses, opinion articles, book chapters and letters to editors were excluded from further analysis. Likewise, articles not written in English; where colitis was primarily investigated using cell lines or animal models (experimental colitis-no human samples); only focused on colitis (mucin expression not investigated); where no controls were included in the study; if there was insufficient data; and if the full article could not be accessed. Clinical case studies were not specifically excluded, Cochrane CENTRAL a database of published clinical trial articles was used as part of the search strategy; however, papers were excluded based on the exclusion criteria stated (none of the clinical case studies identified through the search explored the relationship between mucins and colitis). Subsequently no clinical case studies could be included.

\subsection{Study Quality Assessment}

All included articles were peer-reviewed. Risk of bias was assessed as part of the appraisal stage during data extraction. A risk of bias scoring system was designed for this systematic review in order to rule out common forms of bias which are encountered in scientific research. The criteria assessed the impact of sample size, sample variability, selection bias, comparability of sample groups (patient samples and controls), reproducibility of investigations and reporting bias. Study quality was ranked on a scale from 0 (low quality) to 6 (high quality).

\subsection{Data Synthesis}

The focus of this review was the relationship between mucin activity and colitis, and therefore a narrative account of findings from the included studies detailing the mucins analysed and the fate of mucins during colitis was recorded. Findings and data from studies were tabulated. Quantitative synthesis of results using meta-analysis was not performed because the presentation of quantitative analysis (methods used for quantitative analysis and units) varied substantially across articles. Therefore, procedural bias was eliminated from this review by omitting meta-analysis. 


\section{Results}

\subsection{Search Results}

Figure 1 details a flowchart of the study selection [27]. A total of 5497 articles were identified by conducting searches on databases (Cochrane CENTRAL $=31$, Ovid MEDLINE $=1237$, PubMed $=2048$, Web of Science $=2181$ ). A total of 3517 duplicates were removed, then titles and abstracts of the remaining articles were screened. Following the screening process, 1980 articles were rejected based on the exclusion criteria because they were reviews, book chapters, opinion articles, not written in English or because the focus of the articles was unrelated to the aim and topic to be addressed in this systematic review. For the next stage of the selection process, a full text eligibility assessment was carried out on the 60 articles that remained after the initial screening process. Employing the eligibility criteria, 44 articles were excluded from further analysis and 14 that met the inclusion criteria were identified for subsequent data analysis.

Ten articles were excluded because the full text was inaccessible, therefore, assessment for eligibility criteria and subsequent analysis would not have been possible. Seven articles were also excluded because the studies did not include controls. Others were excluded because instead of including control groups, they compared mucin expression in the colonic mucosa of patients with UC to that of patients with CD. For example, Dorofeyev et al. [28] observed that in UC, mucin gene expression decreased in severe disease and the reverse of this was noted for CD. Similarly, Hensel et al. [29], which explored the differential expression of MUC1 and MUC2 in pediatric patients with IBD, was excluded; although a control cohort was included in this study, the findings were presented as differences between the expression of mucins at different severities (inflamed/non-inflamed) of CD and UC, while these studies are informative for our understanding of characteristic differences within the intestinal microenvironment of patients with UC and CD, the differences that may exist between healthy controls and patients with IBD are inconclusive from the findings presented. Therefore, the relationship between UC and mucins could not be accurately analysed and elucidated. Although some studies produced noteworthy results relating to the fate of intestinal mucin genes during colitis, they were excluded from further analysis because mucin gene expression was not investigated or documented. For example, Swallow et al. [30] determined that MUC2 allele length is not associated with disease pathogenesis, whilst Kyo et al. [31] detected rare MUC3 alleles in UC patients which they suggested may be associated with disease pathogenesis. In addition to the articles included through database searching [32-45] and screening, 2 more papers were identified through citation chaining $[46,47]$ and included in the analysis group (Figures 1 and 2). The citation network generated using output data from the citation chaining process highlights the connections between the included studies. The more recent studies cited some of the older studies (Figure 2). 


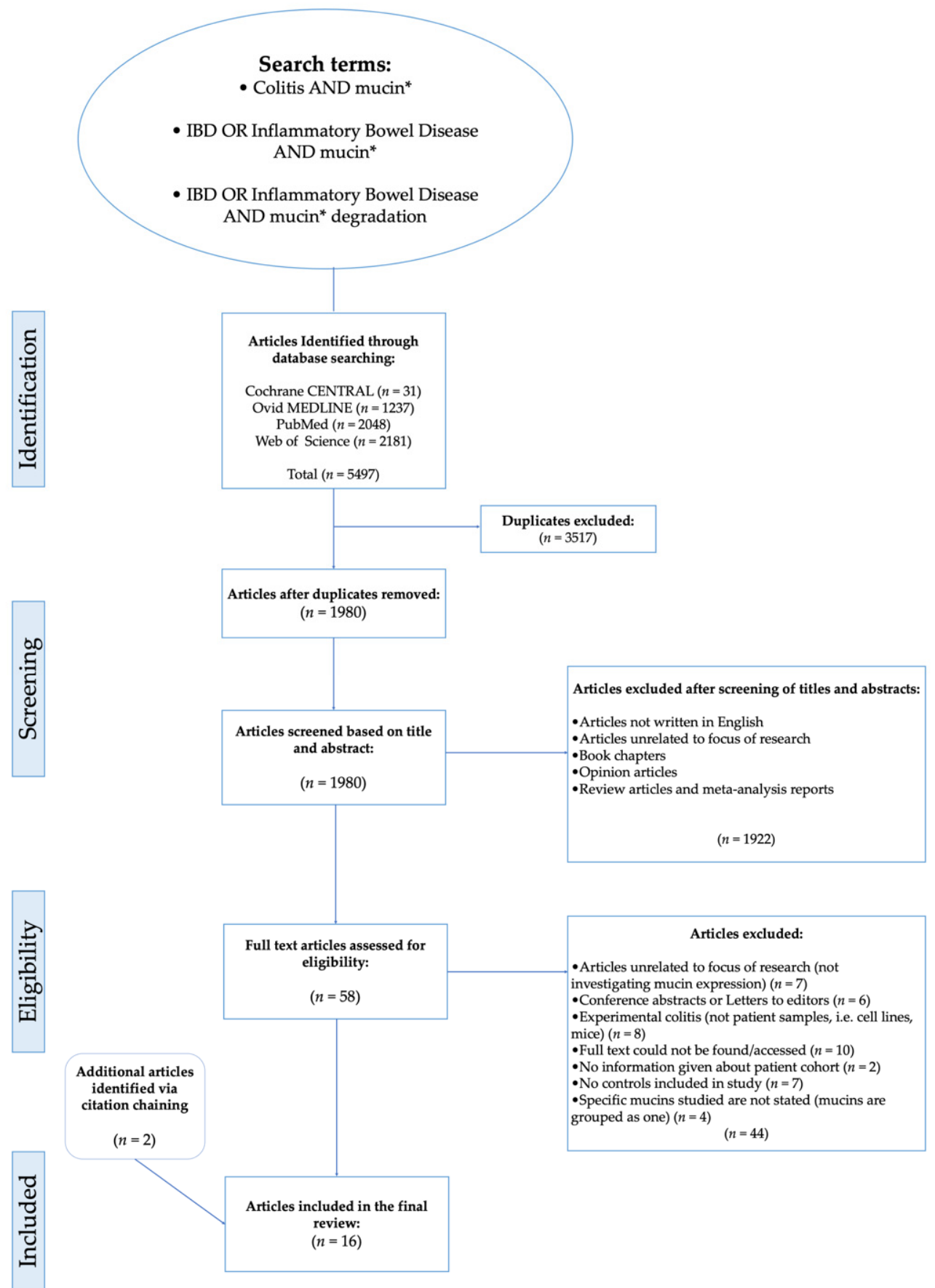

Figure 1. Flow chart showing steps of search process leading to the inclusion of articles for analysis. Boolean operators and search modifiers were using to optimise the retrieval of articles in the search strategy: 'AND' allows for citations containing all search terms to be retrieved, OR' can produce citations containing at least one of a group of search terms. Therefore, 'OR' was used here where words were similar/related e.g. IBD and Inflammatory Bowel Disease. Truncation as denoted by asterix $\left(^{*}\right)$ was used to find citations including words with the same stem e.g. mucin, mucins, mucinase. 


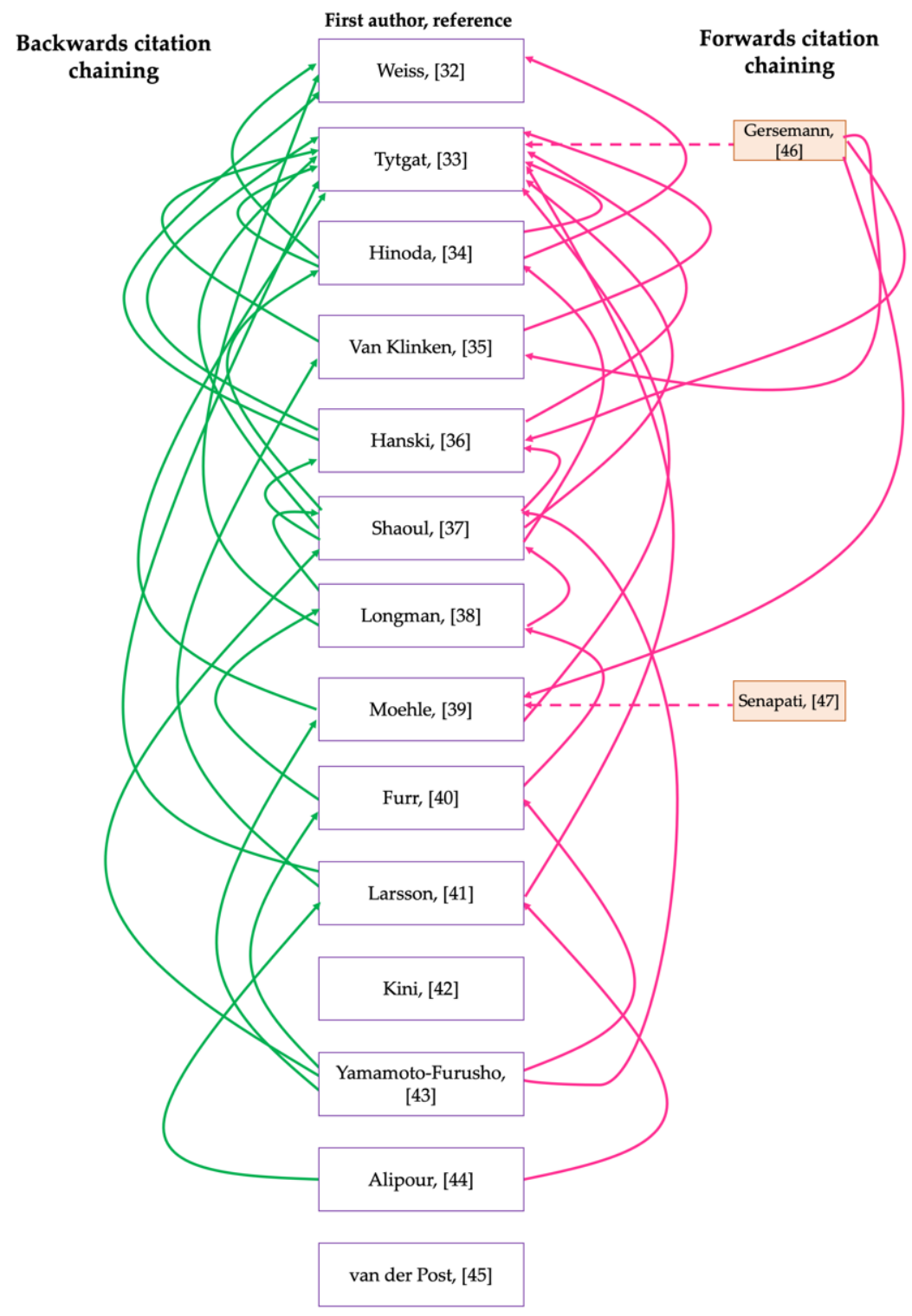

Figure 2. Citation network showing the output data of citation chaining process using key articles that were included for analysis following database searches and screening. Backwards citation chaining output data is presented on the left-hand side, here an arrow is pointed from the key articles used for citation chaining towards an article that the key article cites. Forwards citation chaining output data is presented on the righthand side, here an arrow is pointed towards the key article used for citation chaining from an article that has cited the key article. Dashed arrows are used to highlight articles that were identified by citation chaining.

\subsection{Overview of Studies Selected for Analysis}

The final 16 included articles were all peer-reviewed case-control studies, published between 1990 and 2020, assessing the role of specific mucins during UC by carrying out various investigations using resected biopsy samples from a cohort of patients (Table 1). $50 \%(n=16)$ of the studies were conducted in European countries, whilst $31 \%(n=16)$ were conducted in North America and 19\% $(n=16)$ in Asia. None of the identified studies were performed in African or Southern American countries. $44 \%$ of the studies were published in the last 10 years. 
Table 1. Summary of the study design and sample characteristics for each of the included articles.

\begin{tabular}{|c|c|c|c|c|c|c|c|}
\hline \multicolumn{3}{|c|}{ Identification } & \multicolumn{3}{|c|}{ Population } & \multicolumn{2}{|c|}{ Methods Used } \\
\hline First Author, Reference & Year & Country & Control Samples & Nature of Control Samples & Patient Samples & $\begin{array}{c}\text { Diagnosis-Disease } \\
\text { Severity/Scoring Indices }\end{array}$ & Study Design \\
\hline Weiss, [32] & 1996 & USA & 1 & $\begin{array}{l}\text { Resected tissue from patient with } \\
\text { colon diverticular disease }\end{array}$ & 8 & $\begin{array}{l}\text { Method of Diagnosis/ } \\
\text { Scoring Indices used are not } \\
\text { stated }\end{array}$ & Case-control study \\
\hline Tytgat, [33] & 1996 & Netherlands & 7 & $\begin{array}{l}\text { Negative history of IBD (colon } \\
\text { appeared normal endoscopically } \\
\text { and histologically) }\end{array}$ & $\begin{array}{l}\text { Active UC: 6, Inactive } \\
\text { UC (remission): } 6\end{array}$ & $\begin{array}{l}\text { Truelove and Richards } \\
\text { Index }\end{array}$ & Case-control study \\
\hline Hinoda, [34] & 1998 & Japan & 14 & $\begin{array}{l}\text { Normal colonic tissue obtained } \\
\text { post-mortem (from autopsies) }\end{array}$ & 31 & Matts Score & Case-control study \\
\hline Van Klinken, [35] & 1999 & Netherlands & 12 & $\begin{array}{l}\text { Tissue resected from patients } \\
\text { diagnosed with Irritable Bowel } \\
\text { Syndrome, hyperplastic polyps or } \\
\text { diverticulosis but with negative } \\
\text { history of IBD }\end{array}$ & $\begin{array}{l}\text { Active UC: } 13 \text {, Inactive } \\
\text { UC (remission): } 12\end{array}$ & Truelove and Richards & Case-control study \\
\hline Hanski, [36] & 1999 & Germany & 13 & $\begin{array}{l}\text { Histologically normal mucosae } \\
\text { samples }\end{array}$ & 70 & $\begin{array}{l}\text { Matts Score (degree of } \\
\text { inflammation), Remmele } \\
\text { and Stegner } \\
\text { (immunoreactive score for } \\
\text { immunohistochemistry) }\end{array}$ & Case-control study \\
\hline Longman, [38] & 2006 & UK & 17 & $\begin{array}{l}\text { Tissue resected from patients } \\
\text { undergoing elective colorectal } \\
\text { resection surgery but with } \\
\text { negative history of IBD }\end{array}$ & 40 & Truelove and Witts Criteria & Case-control study \\
\hline Moehle, [39] & 2006 & Germany & 14 & $\begin{array}{l}\text { Tissue resected from patients } \\
\text { following colonoscopy ( } 8 \text { with no } \\
\text { tissue abnormalities; remaining } \\
\text { samples from patients with } \\
\text { diverticulitis, polyposis coli, } \\
\text { lymphoid tissue-lymphoma, } \\
\text { carcinoma, diverticulosis, } \\
\text { eosinophilic colitis, infectious } \\
\text { colitis }\end{array}$ & $\begin{array}{l}\text { Active UC: } 14 \text {, Inactive } \\
\text { UC (remission): } 5\end{array}$ & $\begin{array}{l}\text { Diagnosis based on clinical } \\
\text { features and } \\
\text { radiologic/endoscopic } \\
\text { findings }\end{array}$ & Case-control study \\
\hline Gersemann, [46] & 2009 & Germany & 21 & $\begin{array}{c}\text { Tissue resected from patients } \\
\text { undergoing routine colonoscopy } \\
\text { (specific reasons for colonoscopy } \\
\text { are not outlined) }\end{array}$ & $\begin{array}{l}\text { Active UC: } 25 \text { Inactive } \\
\text { UC: } 15\end{array}$ & $\begin{array}{c}\text { Method of } \\
\text { Diagnosis/Scoring Indices } \\
\text { used are not stated }\end{array}$ & Case-control study \\
\hline
\end{tabular}


Table 1. Cont.

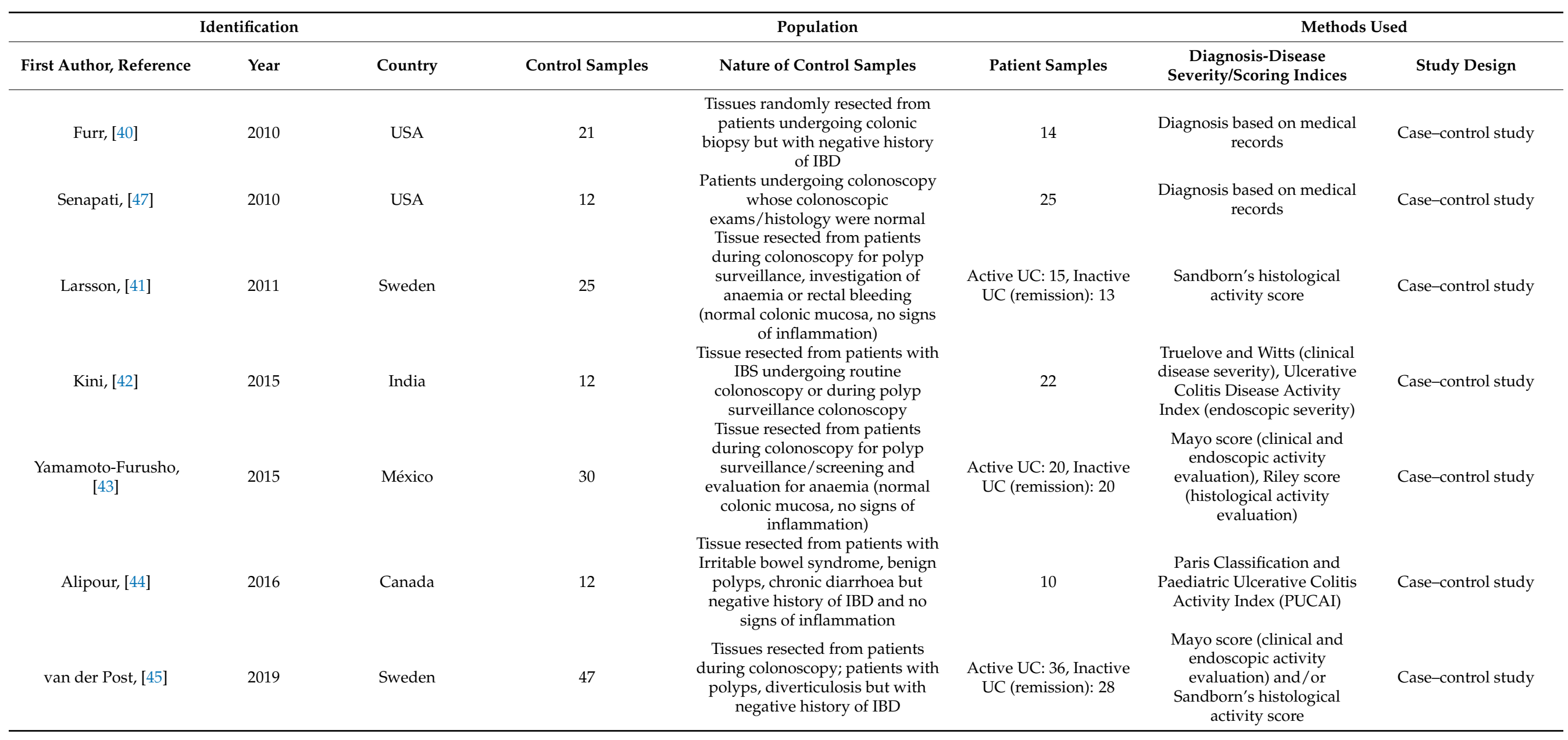


Three of the included studies $[37,40,44]$ were carried out using specimens resected from individuals with paediatric IBD. Eight articles focused solely on the relationship between MUC2 and colitis, whilst five articles studied MUC2 and a selection of other mucins in colitis. Three of the included articles did not study MUC2 at all, one investigated MUC1 [40], whilst the another investigated MUC12, MUC16 and MUC20 in UC [43] and finally one investigated MUC17 [47]. In order to create a timeline of the findings and to understand how the findings from different studies may be related to each other, a table listing the included studies in chronological order was produced (Table 2).

Table 2. Summary of the purpose for articles included for analysis and key findings.

\begin{tabular}{|c|c|c|c|c|}
\hline First Author, Reference & Purpose of Study & MUC Gene Investigated & $\begin{array}{l}\text { Measuring MUC } \\
\text { Expression }\end{array}$ & Key Findings \\
\hline Weiss, [32] & $\begin{array}{l}\text { To investigate effect of } \\
\text { inflammation on } \\
\text { expression of mucin genes } \\
\text { at cellular level }\end{array}$ & MUC2, MUC3 & $\begin{array}{l}\text { In-situ hybridisation with } \\
\text { RNA probes }\end{array}$ & $\begin{array}{c}\text { MUC2 and MUC3 } \\
\text { expression in colonic } \\
\text { mucosa is independent of } \\
\text { inflammation }\end{array}$ \\
\hline Tytgat, [33] & $\begin{array}{l}\text { To study regulation of } \\
\text { MUC2 expression in } \\
\text { patients with UC } \\
\text { compared with controls }\end{array}$ & MUC2 & $\begin{array}{c}\text { MUC2 precursor } \\
\text { quantified by SDS-PAGE, } \\
\text { total MUC2 by dot blot, } \\
\text { in-situ hybridisation with } \\
\text { RNA probes to quantify } \\
\text { MUC2 mRNA }\end{array}$ & $\begin{array}{l}\text { Inefficient translation of } \\
\text { MUC2 mRNA may lead to } \\
\text { the reduction in MUC2 } \\
\text { synthesis observed in } \\
\text { active UC }\end{array}$ \\
\hline Hinoda, [34] & $\begin{array}{c}\text { To determine if MUC2 } \\
\text { protein expression is } \\
\text { altered in UC }\end{array}$ & MUC2 & $\begin{array}{l}\text { MUC2 protein detected by } \\
\text { Immunohistochemistry }\end{array}$ & $\begin{array}{c}\text { Decreased MUC2 protein } \\
\text { production and expression } \\
\text { in active UC is associated } \\
\text { with undifferentiated } \\
\text { goblet cells }\end{array}$ \\
\hline Van Klinken, [35] & $\begin{array}{l}\text { To determine whether } \\
\text { there are alterations in } \\
\text { MU2 sulphation and } \\
\text { secretion in active UC }\end{array}$ & MUC2 & $\begin{array}{c}\text { Analysis and } \\
\text { quantification of total } \\
\text { MUC2 using SDS-PAGE } \\
\text { and dot blotting }\end{array}$ & $\begin{array}{l}\text { Absolute amount of } \\
\text { MUC2 secreted is } \\
\text { decreased and mucins are } \\
\text { under-sulphated in active } \\
\text { UC }\end{array}$ \\
\hline Hanski, [36] & $\begin{array}{l}\text { To study alterations in } \\
\text { MUC2 expression in UC } \\
\text { patient colonic tissue }\end{array}$ & MUC2 & $\begin{array}{l}\text { MUC2 protein detected by } \\
\text { immunohistochemistry } \\
\text { and MUC2 mRNA } \\
\text { detected using in-situ } \\
\text { hybridisation }\end{array}$ & $\begin{array}{l}\text { Increase in MUC2 protein } \\
\text { detection in UC samples } \\
\text { may be related to } \\
\text { reduction in post } \\
\text { transcriptional } \\
\text { modification }\end{array}$ \\
\hline Shaoul, [37] & $\begin{array}{l}\text { To investigate alterations } \\
\text { in expression and } \\
\text { distribution of MUC2, } \\
\text { MUC5AC, trefoil factor } 1 \\
\text { (TFF1) in UC }\end{array}$ & MUC2, MUC5AC & $\begin{array}{c}\text { PAS/Alcian blue } \\
\text { immunohistochemistry }\end{array}$ & $\begin{array}{c}\text { Immature (poorly } \\
\text { glycos-ylated) MUC2 is } \\
\text { expressed in UC colonic } \\
\text { mucosa depleted of goblet } \\
\text { cells }\end{array}$ \\
\hline Longman, [38] & $\begin{array}{l}\text { To investigate alterations } \\
\text { in the expression of mucin } \\
\text { genes and trefoil peptide } \\
\text { genes in UC }\end{array}$ & MUC1-6 & $\begin{array}{l}\text { Immunohistochemistry } \\
\text { and in-situ hybridisation }\end{array}$ & $\begin{array}{c}\text { MUC1 expression } \\
\text { upregulation is associated } \\
\text { with severe UC and there } \\
\text { is a reduction of MUC2 } \\
\text { expression in UC }\end{array}$ \\
\hline Moehle, [39] & $\begin{array}{l}\text { To characterize changes in } \\
\text { mucin expression and } \\
\text { identify allelic variants of } \\
\text { MUC genes in UC }\end{array}$ & MUC1-20 & $\begin{array}{c}\text { Affymetrix } \\
\text { DNA-microarray analysis } \\
\text { and RT-PCR }\end{array}$ & $\begin{array}{l}\text { MUC12 mRNA expression } \\
\text { is downregulated in UC } \\
\text { and is independent of } \\
\text { inflammation }\end{array}$ \\
\hline Gersemann, [46] & $\begin{array}{c}\text { To understand the } \\
\text { mechanisms involved } \\
\text { with goblet cell } \\
\text { differentiation and mucin } \\
\text { production in IBD }\end{array}$ & MUC1, MUC2, MUC4 & RT-PCR & $\begin{array}{l}\text { Impairments in goblet cell } \\
\text { differentiation factor } \\
\text { induction in UC correlates } \\
\text { with a reduction in mucin } \\
\text { synthesis. }\end{array}$ \\
\hline Furr, [40] & $\begin{array}{l}\text { To determine whether } \\
\text { MUC1 expression is } \\
\text { altered in IBD }\end{array}$ & MUC1 & $\begin{array}{l}\text { Immunochemistry using } \\
\text { anti-MUC1 anti-bodies }\end{array}$ & $\begin{array}{l}\text { Overexpression and } \\
\text { hypoglycosylation of } \\
\text { MUC1 observed in a } \\
\text { subset of UC patients }\end{array}$ \\
\hline
\end{tabular}


Table 2. Cont.

\begin{tabular}{|c|c|c|c|c|}
\hline First Author, Reference & Purpose of Study & MUC Gene Investigated & $\begin{array}{l}\text { Measuring MUC } \\
\text { Expression }\end{array}$ & Key Findings \\
\hline Senapati, [47] & $\begin{array}{l}\text { To determine the } \\
\text { subcellular localization of } \\
\text { MUC17 in colonic mucosa } \\
\text { and to determine whether } \\
\text { MUC17 expression is } \\
\text { altered in IBD and } \\
\text { neoplastic diseases. }\end{array}$ & MUC17 & $\begin{array}{l}\text { Immunohistochemistry } \\
\text { using anti-MUC17 } \\
\text { polyclonal antibody }\end{array}$ & $\begin{array}{l}\text { MUC17 expression is } \\
\text { reduced in colonic mucosa } \\
\text { of UC patients }\end{array}$ \\
\hline Larsson, [41] & $\begin{array}{l}\text { To determine whether } \\
\text { MUC2 glycosylation is } \\
\text { related to degree of } \\
\text { mucosal inflammation in } \\
\text { UC }\end{array}$ & MUC2 & $\begin{array}{l}\text { SDS-PAGE used to } \\
\text { identify and quantify } \\
\text { MUC2 }\end{array}$ & $\begin{array}{l}\text { Alterations in MUC2 } \\
\text { glycosylation are } \\
\text { associated with } \\
\text { inflammation }\end{array}$ \\
\hline Kini, [42] & $\begin{array}{l}\text { To determine whether } \\
\text { alterations occur in colonic } \\
\text { stem cells during the } \\
\text { pathogenesis of UC and to } \\
\text { determine the impact of } \\
\text { such changes on goblet } \\
\text { cell development and } \\
\text { proteins synthesized by } \\
\text { goblet cells }\end{array}$ & MUC2 & $\begin{array}{l}\text { H\&E, Alcian blue and PAS } \\
\text { immunohistochemistry } \\
\text { staining to detect MUC2 } \\
\text { protein }\end{array}$ & $\begin{array}{l}\text { A reduction in MUC2 } \\
\text { protein within the lower } \\
\text { colonic crypt precedes } \\
\text { inflammation. }\end{array}$ \\
\hline Yamamoto-Furusho, [43] & $\begin{array}{l}\text { To determine if MUC12, } \\
\text { MUC16, MUC20 } \\
\text { expression changes in UC }\end{array}$ & MUC12, MUC16, MUC20 & $\begin{array}{l}\text { MUC gene expression } \\
\text { measured using RT-PCR } \\
\text { and MUC protein } \\
\text { expression measured } \\
\text { using } \\
\text { immunohistochemistry }\end{array}$ & $\begin{array}{l}\text { MUC16, MUC20 } \\
\text { expression increase in UC } \\
\text { and increase in MUC20 } \\
\text { was associated with } \\
\text { remission of UC }\end{array}$ \\
\hline Alipour, [44] & $\begin{array}{l}\text { To assess whether mucosal } \\
\text { barrier defects are } \\
\text { prerequisites to UC }\end{array}$ & MUC2 & $\begin{array}{l}\text { Fluorescence in-situ } \\
\text { hybridisation (FISH) and } \\
\text { immunofluorescence }\end{array}$ & $\begin{array}{l}\text { Reduction in } \\
\text { mucin-containing goblet } \\
\text { cells and mucin } \\
\text { production in UC patients } \\
\text { compared to controls }\end{array}$ \\
\hline van der Post, [45] & $\begin{array}{l}\text { To investigate } \\
\text { compositional alterations } \\
\text { that occur at the adherent } \\
\text { mucus layer in UC }\end{array}$ & MUC2 & $\begin{array}{l}\text { Absolute quantification of } \\
\text { MUC2 using Skyline } \\
\text { (V.3.6.0.1) following mass } \\
\text { spectrometry }\end{array}$ & $\begin{array}{l}\text { Reduction of MUC2 in } \\
\text { active UC associated with } \\
\text { exhaustion of secretory } \\
\text { response of goblet cells to } \\
\text { microbes }\end{array}$ \\
\hline
\end{tabular}

Periodic acid-Schiff/Alcian blue (PAS/Alcian blue), Haematoxylin and eosin (H\&E), Sodium Dodecyl Sulphate-Polyacrylamide Gel Electrophoresis (SDS-PAGE), Real Time Polymerase Chain Reaction (RT-PCR).

\subsection{Critical Appraisal of Included Studies}

The 16 included studies were assessed for bias before further analysis was carried out. Widely used systematic review scoring systems, for example the Cochrane risk of bias scoring system [48] have been designed to assess risk of bias in randomised clinical trials but were incompatible for this systematic review. Therefore, a specific scoring system was designed for this review. The aim of this scoring system was to rule out and take account of, if present, common forms of bias which are encountered in scientific research, in particular in case-control studies. Studies were scored Green-1, Amber-0.5, Red-0 for each category of the scoring system. The criteria for the system consisted of seven categories, and consequently a maximum of seven points could be awarded (Figure 3A). Studies with a larger number of specimens improve the ability to recognise and understand trends Therefore, to determine whether trends were random or consistent both sample size and sample variability were scored for all included articles. In case-control studies big differences between samples from individuals in the case group (which is individuals with UC in the included studies) and controls can lead to over-representation or under representation of results, therefore sample size was assessed as the ratio of patient samples to control samples. Another important factor to consider for case- control studies is the comparability between controls and patient samples, comparability was assessed in terms of the sample type and with reference to patient characteristics (Figure 3A). When considering the reliability of data, it is also important to determine the analytical and 
biological reproducibility of investigations, and so this was also assessed. Although the Cochrane risk of bias scoring system was not used, selection bias and reporting bias can still occur in scientific investigations and therefore these categories were retained for the new scoring system. According to this quality scoring system, the final selection of studies was considered to be high quality (Figure 3B), with the lowest score being $3 / 6$ and three articles scoring $6 / 6$. The mean number of participants with UC (patient cohort) across all included studies was 28 , whilst the mean number of control participants across all studies was 16. Weiss et al. [32] and Hanski et al. [36] scored 0 for sample size because the ratio of their controls to patient samples was 1:8 $(12.5 \%)$ and 13:70 (18.6\%) respectively. The pitfall of the majority of the studies was that the size of their control cohort was less than $50 \%$ the size of the control cohort $[32,34-36,38,47]$ and/or the comparability of patient samples to control samples was limited [32,33,36,41,46,47] although bias arising from sample variability $[32,35,39,40,44]$ and/or selection bias $[32,34,37,44]$ was recorded for a few of the studies. Studies scored 0.5 for comparability between samples if insufficient details were provided about the location of the intestinal/colonic mucosal tissue resected in healthy controls in comparison to the patient cohort and if there was insufficient information provided pertaining to the age ranges of samples from individuals in the control and/or the patient cohort. Weiss et al. [32] scored 0.5 for comparability between sample groups because the control sample tissue they analysed was resected from the small intestine, although UC can affect the ileum, the article does not state whether the UC samples they analysed were also resected from the ileum. Since the structure of mucosal layer in the small intestine and colon have slightly different characteristics [3] and UC rarely affects the small intestine Weiss et al. [32] also scored 0.5 for selection bias. Similarly, Alipour et al. [44] scored 0.5 for selection bias, since they analysed UC samples and control samples from the terminal ileum and the other manuscripts analysed samples from the colon, which is the main organ affected by UC. On the other hand, Van Klinken et al. [35] scored full points for comparability because all samples were resected from individuals in a similar age range and were all sex matched. However, since samples were all obtained from men (no women in patient or control cohort) in the study conducted by Van Klinken et al. [35], limited sample variability exists in this study. Weiss et al. [32] scored 0.5 for sample variability and reporting bias because the results presented were from one biopsy specimen and it was not specified in the paper whether the findings were consistently observed in a significant number of the collected specimens. Alipour et al. [44] scored 0.5 for sample variability and reporting bias, for the same reasons. Likewise, Furr et al. [40] scored 0.5 for sample variability because only $46 \%$ of UC specimens were successfully stained for analysis, but since Furr et al. [40] reported this sample variability, the study was deemed to have no evidence of reporting bias. Since biopsy specimens were resected from UC patients during routine colonoscopy and patient identification was blinded from researchers carrying out investigations, most studies were considered to have no selection bias. Control specimens across the studies were generally resected from individuals with no known history of UC undergoing diagnostic colonoscopy (shown to be negative for IBD) or screening for polyps. It must be noted that although the control samples included across the studies were resected from individuals with no history of IBD, some of the controls were taken from patients with other pathologies (Table 1). Several of the included studies used colonic mucosal tissue resected from patients with benign polyps, irritable bowel syndrome or diverticulosis/diverticulitis [32,35,39,43,44]. On the other hand, Hinoda et al. [36] used colonic mucosal tissue resected from patients post-mortem as control samples. For this reason, Hinoda et al. [34] was scored 0.5 for both selection bias and comparability of sample groups. Shaoul et al. [37] also showed some evidence of selection bias, as they reported that their control samples were taken from a histology library, which they did not justify (there is no information given about the patients that the tissue was resected from) However, Shaoul et al. [37] state that the control samples were from age-matched individuals, this increases the comparability between the sample groups. 
(A)

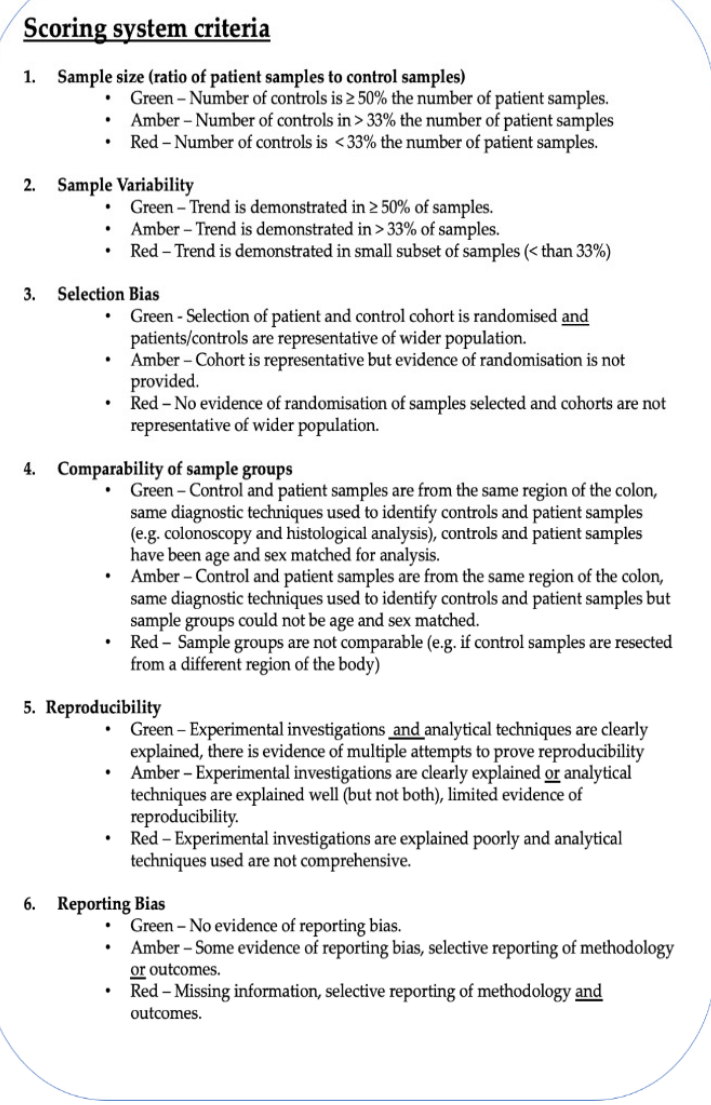

(B)

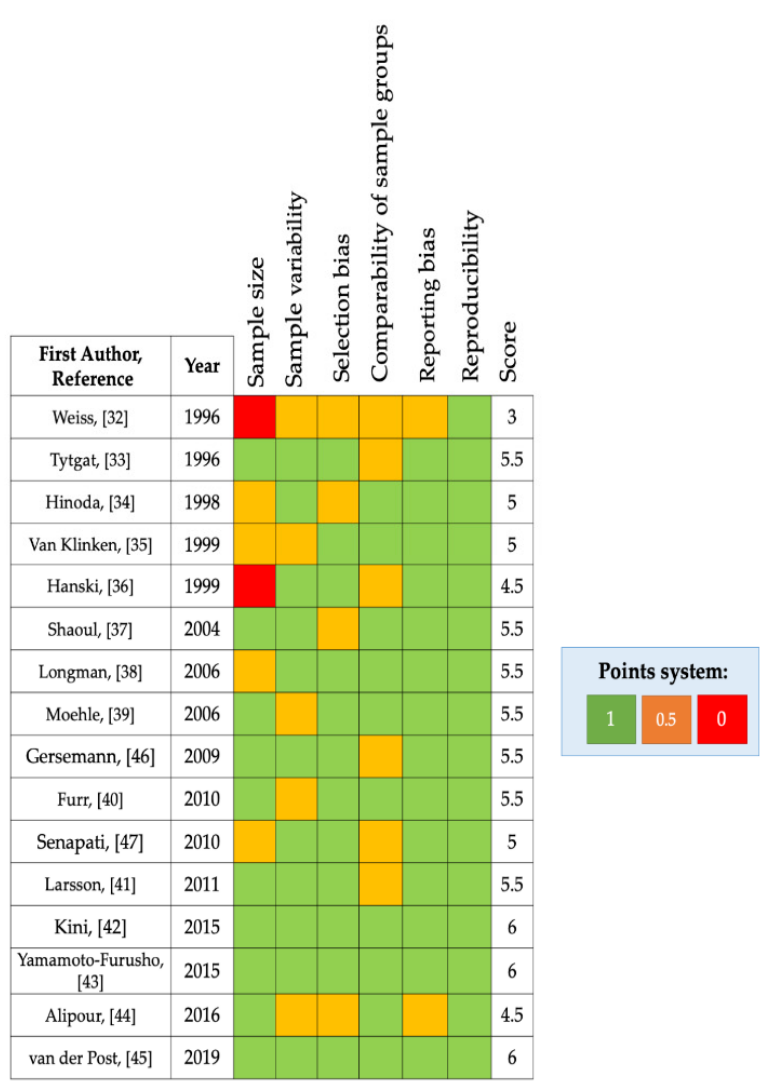

Figure 3. Quality assessment of included studies (A) Scoring system used with categories and information outlining how scores were allocated. (B) List of included studies and scores allocated to each included study using the quality assessment scoring system is shown.

\subsection{MUC2 Expression in Colitis}

MUC2 expression was examined at the nucleic acid and protein level. Eight studies investigated MUC2 mRNA levels in UC in comparison to controls, nine studies investigated MUC2 protein expression levels. Van Klinken et al. [35] and Tytgat et al. [33] both recorded total MUC2. Van Klinken et al. [35] defined total MUC2 as the sum of the detected radiolabelled and non-radiolabelled MUC2 protein. In contrast, Tytgat et al. [33] defined total MUC2 as the sum of MUC2 precursor and mature, fully glycosylated intracellular MUC2 protein and adherent MUC2 protein. It must also be noted that, the methodological techniques employed to measure MUC2 expression varied across the studies depending on the purpose of the study, as highlighted in Table 2. The majority of the studies used in situ hybridisation and/or immunohistochemistry to detect MUC2 mRNA and/or MUC2 protein respectively. However, two studies also employed RT-PCR $[39,46]$ to quantify gene expression by measuring MUC2 mRNA levels.

\subsubsection{MUC2 mRNA Expression}

Several of the studies found that MUC2 mRNA expression levels were unaffected by UC (Figure 3A). Weiss et al. [32] were the first study to use in situ hybridisation to examine whether there were any changes in the cellular distribution of MUC2 as a result of IBD. Concordant with published data, through histological analysis, Weiss et al. [32] observed that MUC2 mRNA was expressed in goblet cells of normal colonic tissue. The pattern of distribution of MUC2 mRNA remained the same in colonic tissue from individuals with UC and the same study reported no apparent differences in the expression of MUC2 mRNA between healthy controls and UC. Furthermore, Tytgat et al. [33] quantified MUC2 mRNA 
levels and found that there were no statistically significant differences between the average levels of MUC2 mRNA in UC samples in comparison to controls. To ensure validity of their results, prior to quantification Tytgat et al. [33] carried out control experiments to assess the size and condition of biopsy specimens and to test the viability of the anti-MUC2 antisense probes. Hanski et al. [36] also found no changes in MUC2 mRNA levels between UC samples and controls. Contrary to Weiss et al. [32], Longman et al. [41] observed differences in the cellular distribution of $M U C 2$ mRNA between $\mathrm{UC}$ and controls and reported that an increase in disease severity was associated with a reduction in MUC2 mRNA expression in goblet cells. Similarly, Alipour et al. [44] showed that there was a significant reduction in the mean number of goblet cells expressing MUC2 mRNA and stated that this was related to aberrations in the intestinal epithelia in UC. Interestingly, Gersemann et al. [46] reported that a reduction in goblet cell differentiation led to the attenuation in the induction of MUC2 mRNA synthesis in inflamed samples (Active UC) in comparison to non-inflamed samples, whilst they also observed an increase in MUC2 mRNA when comparing both noninflamed and inflamed UC samples to controls. Whilst, Moehle et al. [39] reported that MUC2 mRNA levels were downregulated in UC, they suggested that this observation may be a result of interpatient variations of mRNA expression levels between samples within study groups (UC and controls).

\subsubsection{MUC2 Protein Expression}

After analysing the findings associated with MUC2 mRNA expression levels, the findings associated with MUC2 protein expression levels were investigated (Figure 3B). In the study conducted by Tytgat et al. [33], when MUC2 precursor (identified as a mass of $600 \mathrm{kDa}$ ) biosynthesis and total MUC2 levels were quantified; the mean values were reduced significantly in samples obtained from patients with active UC in comparison to patients with UC in remission and controls. The study revealed that although these parameters were also decreased in patients with UC in remission, the values were not decreased to the same extent as in patients with active UC and the values were much closer to the values observed for controls, it was therefore suggested that changes in the level of MUC2 biosynthesis may be associated with inflammation and disease severity. Tytgat et al. [33] aimed to understand the regulation of MUC2 expression in UC; based on their findings, they proposed that MUC2 expression is regulated at the translational level. They observed that there was a direct correlation between the reduction in total MUC2 levels and the reduced synthesis of MUC2 precursor, which led them to propose that in active UC translation of MUC2 mRNA is inefficient. Tytgat et al. [33] noted that further investigations are required to distinguish whether this finding is exclusive to UC or whether it occurs as a result of colonic inflammation independent of UC. Hinoda et al. [34] also demonstrated that MUC2 protein expression decreases in active UC, highlighting that it remains unknown whether the alteration leads to the pathogenesis of UC or whether the alteration occurs during the pathogenesis of UC. Interestingly, van der Post et al. [45] determined that structural components of the colonic mucosa, including MUC2 were reduced in regions without inflammation as well as inflamed regions of UC samples. This suggests that the reduction of MUC2 in UC is independent of and may precede inflammation. In agreement with this, when Kini et al. [42] investigated the relationship between the expression of colonic stem cells within non-inflamed regions of the lower crypt, they recorded that a 2 -fold decrease in stem cells correlated with a reduction in MUC2 protein expression. Kini et al. [42] suggested that this reduction of MUC2 protein precedes inflammation and may be related to a reduction in the differentiation of goblet cells. However, Kini et al. [42] also proposed that the reduction in MUC2 protein is dependent on signalling pathways at different colonic niches, since the study also found no change in goblet cell markers at the upper colonic crypt in UC patient samples in comparison to control samples. Hanski et al. [36] suggested that changes in MUC2 protein expression may occur as a result of a long-term aberration in the post-transcriptional modification of MUC2. Although Hanski et al. [36] observed no changes in MUC2 mRNA levels between UC and control samples, 
the study found an increase in the level of MUC2 protein in active UC compared to UC in remission and controls. Thus, Hanski et al. [36] proposed that the increase in MUC2 protein may be related to an inflammatory pathway which leads to rapid aberrant posttranscriptional modifications prior to translation of MUC2 mRNA to MUC2 protein. The resulting proteins observed by Hanski et al. [36] were hypoglycosylated and/or poorly sulphated. Similarly, Van Klinken et al. [35] reported that MUC2 protein levels were reduced in active UC because MUC2 was under sulphated during synthesis and the reduced sulphate incorporation renders mucins more susceptible to degradation. Although Shaoul et al. [37] did not record changes in MUC2 protein expression levels, they reported that inflammatory damage resulted in the expression of hypoglycosylated MUC2 protein in what appeared to be immature goblet cells. Larsson et al. [41] also recorded no significant differences in relative mean amounts of MUC2 protein between UC patients and controls.

\subsubsection{Goblet Cells and MUC2}

The included studies also explored whether differences existed in goblet cells in the colonic mucosa of UC patients compared to controls. Tytgat et al. [33] proposed that during active UC goblet cells could not efficiently synthesise MUC2 protein in comparison to during remission or in absence of UC. A change in efficiency of MUC2 protein production in active UC was also described by van der Post et al. [45]. In their study they performed microbial challenge of goblet cells by stimulating samples with the bacterial synthetic lipopeptide TLR2 ligand, Pam3CysSerLys4 $\left(\mathrm{P}_{3} \mathrm{CSK}_{4}\right)$. They found that in active UC this led to the attenuation of goblet cell secretory action, and therefore a reduction in secretion of MUC2, and suggested this contributes to the structural weakening of the colonic mucosa. Hinoda et al. [34] on the other hand, showed that the presence of aberrant (poorly differentiated) goblet cells in active UC results in decreased MUC2 protein production. Concordant to this, Gersemann et al. [46] observed a reduction in the percentage of goblet cells in patients with UC when compared to controls. By examining the mRNA expression levels of goblet cell differentiation factors; Helix-loop-helix protein (hATH-1) and Krüppel-like factor 4 (KLF4), Gersemann et al. [46], proposed an association between impairments in goblet cell differentiation and reduced mucin synthesis in patients with UC. The study found that goblet cell differentiation and subsequent mucin synthesis is particularly reduced in inflamed UC samples. Kini et al. [42] also investigated the role of goblet cell differentiation marker KLF4, however, they noted that the relative expression of KLF4 in UC patient samples was not significantly different from controls. Kini et al. [42] identified differences between the differentiation of goblet cells in the lower crypt and upper crypt of colonic biopsy tissue. Although Kini et al. [42] noted no significant changes in the upper crypt, they reported a reduction in stem cells and enteroendocrine cells in the lower crypt, which may be involved in goblet cell differentiation and synthesis of MUC2. Whilst, Shaoul et al. [37] demonstrated that in samples from paediatric UC patients, MUC2 protein levels were preserved (unaltered). However, the protein was expressed in a hypoglycosylated form in secretory granules of cells, which were not phenotypically goblet cells, but which may be immature goblet cells [37]. An alteration of MUC2 protein glycosylation was also reported by Larsson et al. [41], who stated that there were two glycan profiles of MUC2. In the study Larsson et al. [41] noted that MUC2 protein of patients with active UC were composed of smaller glycans than in UC in remission and controls. The study [41] also suggested that glycotransferases in the goblet cell secretory apparatus or mucin glycan degrading enzymes in the colon may be responsible for the different glycan profiles.

\subsection{Membrane-Associated Mucins in Colitis}

It has been well documented that the secretory mucin, MUC2 is the predominant mucin in the colonic mucosa of healthy individuals and individuals with UC [3,25]. A few of the included articles investigated the role of membrane-associated mucins in UC (Figure 4C). MUC1 is expressed at low levels in colonic epithelial cells [35,41]. However, Longman et al. [41] demonstrated that in samples from patients with active UC, MUC1 
expression was upregulated and MUC1 mRNA localised at crypt abscesses. Gersemann et al. [46] also reported an upregulation of $M U C 1 \mathrm{mRNA}$ in samples from inflamed and non-inflamed UC patient samples in comparison to controls, albeit to a lower extent than in CD patient samples. Additionally, Furr et al. [40] determined that this altered expression of MUC1 in the colon is exclusive to IBD, as aberrant MUC1 was not detected when investigations were carried out with non-IBD abnormal colonic biopsy specimens (from patients with celiac disease). As observed for MUC2 mRNA expression, Weiss et al. [32] reported that MUC3 mRNA expression levels were unaltered during active UC. Both Weiss et al. [32] and Longman et al. [38] showed that MUC3 mRNA is expressed at the colonic surface epithelium and colonic crypts, despite inflammation. Longman et al. [41] also showed that MUC4 mRNA was strongly expressed in the cytoplasm of colonic epithelia in UC and control samples. Further to this Gersemann et al. [46] recorded an upregulation of MUC4 in UC patient samples. Yamamoto-Furusho et al. [43] conducted a study aiming to understand the potential role of MUC12, MUC16 and MUC20 in UC, since very few studies have investigated these mucins in UC. The study found that, MUC12 mRNA expression was significantly reduced in active UC in comparison to UC in remission and controls and this reduction was associated with the perturbation of the colonic mucosa. When Moehle et al. [39] investigated MUC12 mRNA expression in UC, they recorded concordant results. Yamamoto-Furusho et al. [43] also reported an increase in MUC16 mRNA in active UC and UC in remission compared to controls. However, this study did not find an association between MUC16 expression and the clinical presentation of UC. On the contrary, Yamamoto-Furusho et al. [43] found a link between the expression of MUC20 in UC and remission, the expression of MUC20 was increased in samples from patients with UC in remission in comparison with patients with active UC and controls. The study suggested that the increase in MUC20 mRNA expression is part of a protective mechanism. The expression of MUC17 in UC was investigated by both Moehle et al. [39] and Senapati et al. [47]. Moehle et al. [39] observed a downregulation of MUC17 mRNA in patient UC samples in comparison to controls. Through immunohistochemical analysis, Senapati et al. [47] observed a significant reduction in the expression of MUC17 protein in UC patient samples in comparison to controls, this study also examined differences in the localisation of MUC17. Senapati et al. [47] recorded loss of expression of MUC17 within the colonic crypts of UC samples and sparse expression on the surface colon columnar cells, which was markedly different to the controls which had strong expression of MUC17 within the crypt epithelial cells. The study [47] also determined that this difference in MUC17 expression was associated with inflammation but was not restricted to patients with UC, as they recorded a similar reduction and presentation of MUC17 expression within colonic tissue resected from patients with Ischaemic Colitis.

\subsection{MUC5AC in Colitis}

MUC5AC is a secretory mucin normally expressed in the gastric mucosa [37]. Since it has been documented that MUC5AC is expressed in goblet cells of the small intestine when inflammation is present, Shaoul et al. [37] aimed to determine whether MUC5AC is expressed in the colonic mucosa of individuals with UC and reported that MUC5AC mRNA co-expressed with MUC2 mRNA in goblet cells in UC samples. On the other hand, Longman et al. [41] could not detect MUC5AC mRNA in UC samples. 
(A)

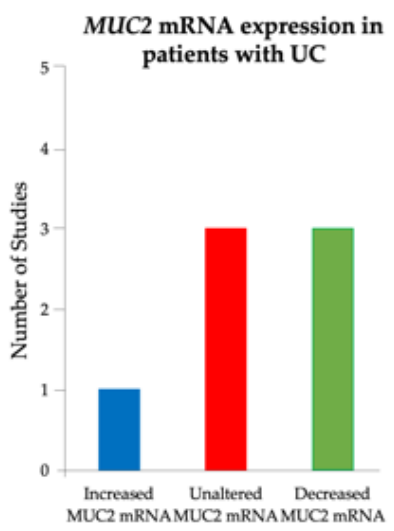

(B)

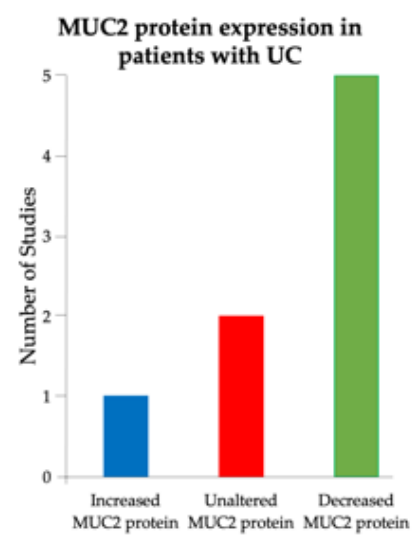

\begin{tabular}{|c|c|c|}
\hline $\begin{array}{c}\text { First Author, } \\
\text { Reference }\end{array}$ & Year & Observation \\
\hline Weiss, [32] & 1996 & $\begin{array}{c}\text { Unaltered MUC2 } \\
\text { mRNA }\end{array}$ \\
\hline Tytgat, [33] & 1996 & $\begin{array}{c}\text { Unaltered MUC2 } \\
\text { mRNA }\end{array}$ \\
\hline Hanski, [36] & 1999 & $\begin{array}{c}\text { Unaltered MUC2 } \\
\text { mRNA }\end{array}$ \\
\hline Longman, [38] & 2006 & $\begin{array}{c}\text { Decreased MUC2 } \\
\text { mRNA }\end{array}$ \\
\hline Moehle, [39] & 2006 & $\begin{array}{c}\text { Decreased MUC2 } \\
\text { mRNA }\end{array}$ \\
\hline Gersemann, [46] & 2010 & $\begin{array}{c}\text { Increased } \\
\text { MUC2 mRNA }\end{array}$ \\
\hline Alipour, [44] & 2016 & $\begin{array}{c}\text { Decreased MUC2 } \\
\text { mRNA }\end{array}$ \\
\hline
\end{tabular}

\begin{tabular}{|c|c|c|}
\hline $\begin{array}{c}\text { First Author, } \\
\text { Reference }\end{array}$ & Year & Observation \\
\hline Tytgat, [33] & 1996 & $\begin{array}{c}\text { Decreased MUC2 } \\
\text { protein }\end{array}$ \\
\hline Hinoda, [34] & 1998 & $\begin{array}{c}\text { Decreased MUC2 } \\
\text { protein }\end{array}$ \\
\hline Van Klinken, [35] & 1999 & $\begin{array}{c}\text { Decreased MUC2 } \\
\text { protein }\end{array}$ \\
\hline Hansk,i [36] & 1999 & $\begin{array}{c}\text { Increased MUC2 } \\
\text { protein }\end{array}$ \\
\hline Shaoul, [37] & 2004 & $\begin{array}{c}\text { Unaltered MUC2 } \\
\text { protein }\end{array}$ \\
\hline Larsson, [41] & 2011 & $\begin{array}{c}\text { Unaltered MUC2 } \\
\text { protein }\end{array}$ \\
\hline Kini, [42] & 2015 & $\begin{array}{c}\text { Decreased MUC2 } \\
\text { protein }\end{array}$ \\
\hline van der Post, [45] & 2019 & $\begin{array}{c}\text { Decreased MUC2 } \\
\text { protein }\end{array}$ \\
\hline & & \\
\hline
\end{tabular}

(C)

\begin{tabular}{|c|c|c|c|c|c|c|c|c|c|c|c|c|}
\hline $\begin{array}{c}\text { First Author, } \\
\text { Reference }\end{array}$ & Year & MUC1 & MUC3 & MUC4 & MUC5AC MUC5B & MUC6 & MUC12 & MUC13 & MUC16 & MUC17 & MUC20 \\
\hline Weiss, [32] & 1996 & & U & & & & & & & & & \\
\hline Shaoul, [37] & 2004 & & & & I & & & & & & & \\
\hline Longman, [38] & 2006 & I & U & U & U & U & U & & & & & \\
\hline Moehle, [39] & 2006 & & & D & D & D & & D & D & & D & D \\
\hline Gersemann, [46] & 2009 & I & & I & & & & & & & & \\
\hline Furr, [40] & 2010 & I & & & & & & & & & & \\
\hline $\begin{array}{c}\text { Senapati [47] } \\
\text { Yamamoto-Furusho, } \\
\text { [43] }\end{array} 2010$ & & & & & & & & & & D & \\
\hline
\end{tabular}

Figure 4. Summary of information reported in articles analyzing differences in mucin expression in active UC compared to controls. (A) Bar chart and table showing observations made by included studies that investigated MUC2 mRNA expression in active UC, with controls as baseline for comparison. (B) Bar chart and table showing observations made by included studies that investigated MUC2 protein expression in active UC, with controls as baseline for comparison. (C) Table showing observations made by included studies that investigated mucin expression levels of mucins other than MUC2. Key: I-Increased expression in comparison to controls, U-Unaltered expression in comparison to controls, D-decreased expression in comparison to controls.

\section{Discussion}

This systematic review was conducted to investigate the relationship between mucins and UC. This review provides detailed analysis of the current published information pertaining to the expression of mucins in the colonic mucosa of individuals with UC. The majority of studies reviewed presented evidence of alterations in the expression of colonic mucins in patients with UC at either the mRNA or protein level and this is summarized in Figure 5. One of the aims of this review was to gain a clearer understanding of the role of MUC2 in the development of UC and to explore the role of MUC2 in the regulation of 
the protective colonic mucosal barrier. Conflicting results were presented by studies with regards to MUC2 mRNA expression (Figure 4A). Out of the seven studies that investigated MUC2 mRNA expression, $14 \%(n=7)$ recorded an increase in MUC2 mRNA in UC whilst $43 \%(n=7)$ of studies observed a decrease and $43 \%(n=7)$ observed no significant difference in MUC2 mRNA. Likewise, data extracted from studies assessing MUC2 protein expression presented mixed findings (Figure $4 \mathrm{~B})$. Whilst $63 \%(n=8)$ reported a reduction, $25 \%(n=8)$ of the studies did not notice a change in expression between UC samples and control samples and $13 \%(n=8)$ recorded an increase in MUC2 protein expression. It is important to note that the methods used for detection of MUC2 mRNA and MUC2 protein expression varied amongst the studies (Table 2) and this may be indicative of the recorded differences in findings. The differences in findings may also be reflective of the differences in cohort demographics (age, gender, ethnicity) or geographical region (studies from 9 different countries were included) since different genetic variants associated with UC have been found in different geographical regions [23].

A) MUC2

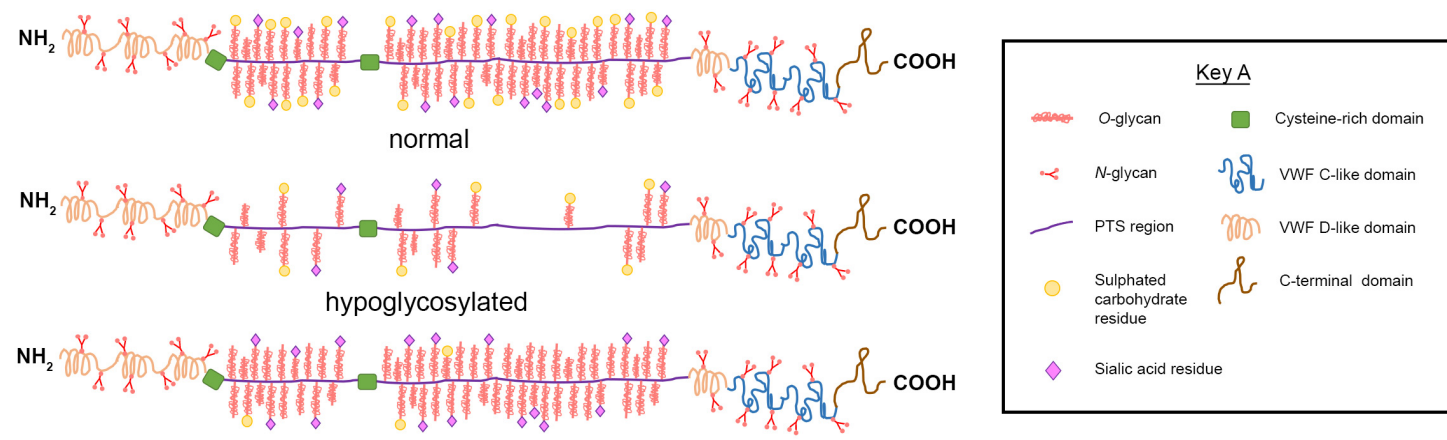

under sulphated

B) Healthy

\begin{abstract}
Ulcerative Colitis
\end{abstract}

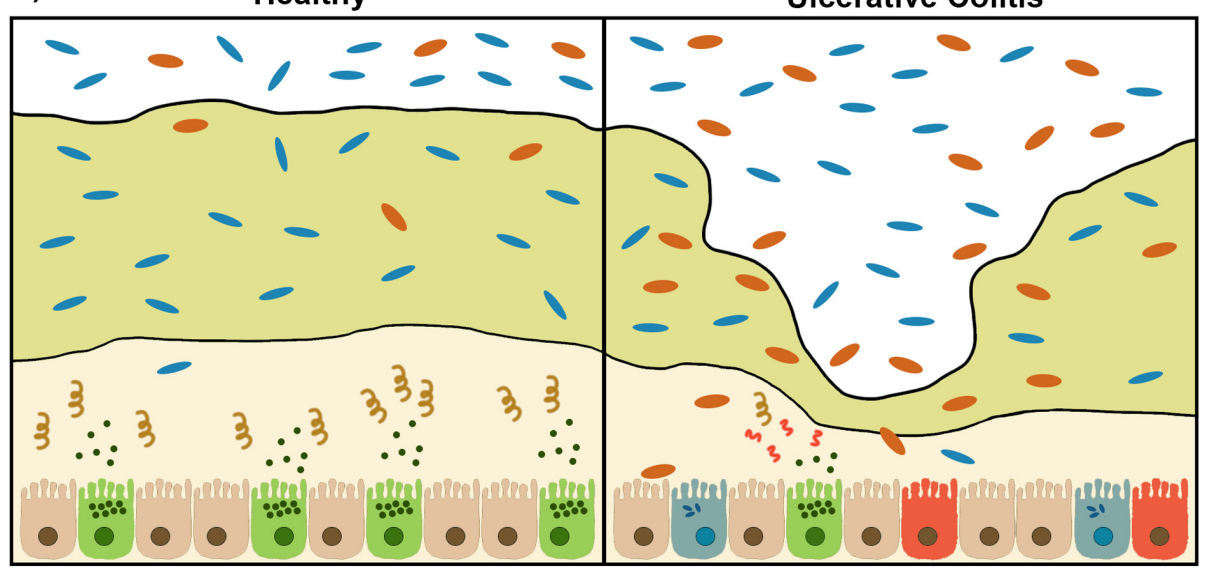

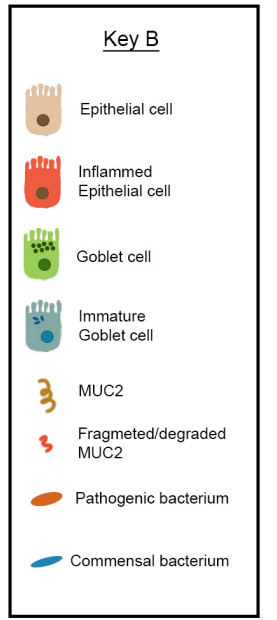

Figure 5. Graphical summary describing the various and dynamic changes in mucin structure and the mucus layer in relation to Ulcerative Colitis (UC). (A) Schematic representations of the mucin MUC2 with domain features explained in Key A. In UC aberrant post translational modifications can lead to hypoglycosylation of MUC2. Hypoglycosylation results in the PTS region being exposed, therefore an unstable form of MUC2 is produced. Mucin glycans can also be under sulphated as a result of aberrant post translation modifications in patients with UC. These aberrations leading to conformational pressure of the MUC2 structure make MUC2 more susceptible to mucin degradation by pathogenic bacteria which are present in the colonic milieu during UC. (B) Schematic representation of the mucosal layer in healthy individuals and patients suffering from UC with features with explained in Key B. There are two sublayers of mucus, the outer layer and the inner layer, mucins are produced by goblet cells in the epithelia and most are expressed within the inner layer of colonic mucus as presented 
on the left-hand side. Mucins in the adherent layer of healthy individuals form interactions which aid to limit the contact between luminal contents and the epithelia. Mucin degradation and mucin synthesis are in equilibrium in healthy individuals. In UC studies have reported a decrease in the number of goblet cells and subsequently a decrease in mucin secretion as shown on the right-hand side of 5B. Studies have also reported an increase in the number of immature goblet cells (poorly differentiated) which leads to the production of unstable mucins (hypoglycosylated and/or under sulphated). The mucosal membrane also becomes perturbed resulting in the infiltration of the luminal microbiota into the inner mucus layer. Increased contact between epithelial cells and bacteria results in inflammation as shown.

It is also important to note that $\mathrm{UC}$ is a heterogenous disease therefore, dysregulation of mucins may differ from one subset of patients to another [20]. UC is heterogenous in terms of the type and level of inflammation observed, with subsequent consequences on disease severity $[9,49]$. Despite this, perturbation of the mucosal membrane and penetration of the luminal microbiota into the inner mucus layer is a common hallmark of UC, highlighting the importance of mucosal integrity in intestinal health $[3,11,49]$. van der Post et al. [45] showed that the increase in microbes at the colonic mucosa during active UC reduced the secretory activity of goblet cells responsible for the production of MUC2. Further to this, it has been shown that several different spatially distinct goblet cell phenotypes are altered in UC [50]. How changes in goblet cell number and phenotype, and subsequent alternations to mucin expression, may impact UC disease severity has yet to be fully elucidated. Differences in study methodology may have also had an impact, for example the nature of controls included in studies varied (Table 1). This may have influenced the observations that were recorded for control samples and consequently the differences in mucin expression and activity reported between controls and patient samples. The histological scoring indices used to categorise patients as having active UC or UC in remission also differed. Some of the scoring indices used included Matts inflammation score, TrueLove and Richards Index, Mayo Score and Sandborn histological score (Table 1).

Additionally, Hanski et al. [36] were the only study to use the Remmele and Stegner immunoreactive score to assess MUC2 protein levels and were the only study to detect an increase in MUC2 protein levels in UC. The lack of a standardised method for the interpretation of immuno-histochemical data for the identification of MUC proteins is highlighted here. The finding from Hanski et al. [36] may indicate that the immunoreactive score is either a more precise method for interpretation or is more susceptible to producing false positives.

Nevertheless, making conclusions solely based on the direction of expression (increases or decreases), is insufficient. The mechanisms behind these findings must be broken down to understand how MUC2 expression is regulated in UC. For example, Tytgat et al. [33] suggested that MUC2 is regulated at the translational level and during active UC MUC2 mRNA is inefficiently translated whereas, Hanski et al. [36] suggested that changes in MUC2 protein expression resulted from inefficient post-transcriptional modification of MUC2. Both of these findings may be related and should be investigated further since, post-transcriptional modifications have an impact on the subsequent translation of $\mathrm{mR}$ NAs to proteins. Although Tytgat et al. [33] reported a reduction in MUC2 protein and Hanski et al. [36] reported an increase, the suggestions made by both studies highlight the importance of understanding how the process of protein production influences mucin structure and in turn the impact of mucin structure on mucin function. For example, aberration of post-translational modifications of mucins in UC such as glycosylation and sulphation have an impact on mucin degradation [35,37,41]. Two of the analysed studies, Shaoul et al. [37] and Larsson et al. [41] described altered glycan profiles of mucins in UC. Further to this, it has been shown that hypoglycosylation and abrupt termination of glycosylation of MUC2 in UC exposes the PTS domain [2,25]. The absence of glycans in the PTS domain makes MUC2 more susceptible to unregulated degradation by proteolytic enzymes. These alterations in mucin structure and subsequent degradation have an impact on the level of mucin expression and could contribute to the thinning of the colonic mucosa in UC $[2,25]$.Moreover, the presence of a thinner colonic mucosa may lead to increased 
infiltration and contact of luminal microbial components with the colonic epithelia, which then drives an inflammatory response.

Although several mucins other than MUC2 have been identified in the healthy colon, this review highlights that the information about the role of these mucins in UC is still very limited. An understanding of the differences in expression and structure of these mucins in the colon of healthy individuals and individuals with UC may enhance our understanding of the role of mucins in UC. Research has shown that a large proportion of the genes encoding secreted mucins, such as MUC2 are clustered on the same chromosomal locus, 11p15 [10]. Therefore, studies directed at assessing the ancestral relationship between mucins, the influence of genetics on mucin transcription and how this directs their function and interaction with each other during UC may be important. One of the included articles, Shaoul et al. [37], described the co-expression of MUC2 and MUC5AC in goblet cells of samples from UC patients. Interestingly, Forgue-Lafitte et al. [51], one of the studies excluded due to the lack of controls, conducted a comparative study of patients with UC and patients with colon cancer. In this study they found that high levels of MUC5AC in UC were associated with inflammation and the presence of pre-cancerous lesions. Since chronic UC can develop into colon cancer, they propose MUC5AC as a surveillance biomarker for the progression of UC. This study highlights the importance of understanding the role of mucins in UC.

Goblet cell depletion has been observed in the colonic mucosa of UC patients and alterations in MUC2 expression have been associated with this depletion of goblet cells and the thinning of the colonic mucosa [25]. The influence of goblet cells on the colonic mucosa and the expression of mucins was assessed in a number of the included articles [33,34,37,41,42,45,46]. It was noted that microbial challenge of goblet cells in active UC led to attenuation of their secretory action and played a role in the structural weakening of the colonic mucosa [45]. The study carried out by van der Post et al. [45] emphasises the importance of enhancing our understanding of the fate of mucins during UC. The microbial challenge is a model of the microbial penetration of the mucus layer that leads to the perturbation of the colonic mucosal epithelia in UC. It has been shown that some pathogenic bacteria are able to infiltrate the host through attachment to mucins, therefore the impact of bacterial colonisation must be evaluated when considering these changes in the mucosal response and goblet cell function $[2,3,18,52,53]$. The increased microbial contact with colonic epithelia in UC is thought to lead to overstimulation of goblet cells resulting in exhaustion of goblet cells and subsequently reduced secretion of mucus [24,45]. This reduction of mucus coupled with an increasing penetration of bacteria has been associated with an increase in inflammation in UC [24]. Consequently, this can lead to more aberrant differentiation of goblet cells, and as stated by Hinoda et al. [34] this results in reduced production of mucins. The findings from these articles collectively highlight the complexity of the interactions and mechanisms that drive the perturbation of the colonic epithelia, leading to aberrant function and differentiation of goblet cells. However, it is evident that the impact of bacterial colonisation and inflammation on goblet cell function and in turn mucin production and expression needs to be studied further. Kini et al. [42] and Gersemann et al. [46], focus on the importance of understanding the pathways and factors involved in the initiation of goblet cell differentiation and the impact of this on mucin synthesis and consequent expression.

Unfortunately, meta-analysis could not be included in this review because during the data extraction process, it was established that articles used varying methods and units to measure mucin expression. Furthermore, some of the included studies used histological analysis rather than quantitative data to make conclusions about mucin expression. It was concluded that because of the large differences in reporting style used across the studies, conducting a meta-analysis by trying to convert data presented to the same format may introduce procedural bias. However, the data presented in this review still provides evidence that mucin expression is altered during UC and highlights the importance of further studies for clarifying the role of mucins in the pathogenesis of UC. Although the role of mucins in the pathogenesis of UC cannot be ignored, it must be noted that 
the aetiology of IBD is multifactorial and this review provides just a snapshot of the full picture. It is therefore important to design investigations that explore the interactions between the mucins and other factors within the colonic milieu, for example models can be designed to investigate these interactions at the molecular level. Collaborative multinational studies investigating the role of mucins in UC patients would also enable a larger number of samples from a wider population of patients (varied geographical distributions) with varying presentations of UC to be analysed. Furthermore, larger studies will provide more precise results as differences in demographics can be accounted for and findings will be easier to generalise. Future studies should ideally be longitudinal, so changes can be monitored throughout the course of the disease although it is recognised that there are significant logistical challenges to such an approach. It is also important to identify how changes in mucin expression and structure may be functionally implicated in disease progression. Therefore, further investigations applying a combination of Single Cell RNA Sequencing (scRNAseq) and pathway enrichment analysis can be geared towards determining upstream factors responsible for the observed changes in mucin expression, activity and structure and the downstream consequences. Chromatin immunoprecipitation (ChIP) assays have also been shown to be a good method for investigating how mucin gene expression is regulated [54]. To complement this, structural changes in the mucus layer should be observed by comparing samples from patients with different severities of disease with samples from healthy controls. Microscopy imaging techniques such as spatial light interference microscopy (SLIM) can be used to determine changes in mucus thickness and mass spectrometry coupled with proteomics can be used to deduce differences that may exist in mucin structure [54]. Employing these strategies to study the changes in mucin expression, activity and structure in patients with UC, may inform the development of new therapeutic targets for the colonic mucosal barrier. Undeniably, this review highlights the necessity of more studies exploring the relationship between UC and mucin expression, activity and structure, since only $44 \%$ of the included studies were published in the last 10 years (Table 1). Looking forward, these studies are required to determine whether the changes in mucin expression in patients with UC are significant and to clarify which changes in mucin expression, activity and structure occur.

\section{Conclusions}

In conclusion, the studies assessed in this systematic review identified alterations in mucin activity, expression, synthesis and structure in colonic biopsy samples from patients with UC. Some of the reviewed publications provided evidence of the reduction in mucin expression levels but this was not reproduced in all investigations. However, this may be explained by differences in the assessment of mucin expression in the included studies. Using the findings of the included articles, this review also drew a connection between the changes in mucin structure that occur as a result of UC and mucin degradation. Further studies are required to explore whether the observed alterations of mucins in UC precede pathogenesis or occur during pathogenesis. Nevertheless, the present systematic review, provides a basis to inform further investigations which may enhance our understanding of how mucin regulation is involved in the pathogenesis of UC.

Author Contributions: The data extraction was carried out by E.B. and checked for any discrepancies by J.A.G and J.F.N. Findings from data extracted from studies were assessed and compared qualitatively. E.B., E.R., M.A.C., J.F.N. and J.A.G. wrote the paper.

Funding: J.F.N. was funded by RCUK/UKRI Rutherford Fund fellowship (MR/R024812/1) and E.R. acknowledges a PhD fellowship from the Wellcome Trust (215027/Z/18/Z). J.A.G. was funded by MRC research grant (MR/R017662/1).

Conflicts of Interest: The authors declare no conflict of interest. 


\section{References}

1. Strous, G.J.; Dekker, J. Mucin-Type Glycoproteins. Crit. Rev. Biochem. Mol. Biol. 1992, 27, 57-92. [CrossRef] [PubMed]

2. Corfield, A.P. Mucins: A Biologically Relevant Glycan Barrier in Mucosal Protection. Biochim. Biophys. Acta 2015, 1850, $236-252$. [CrossRef] [PubMed]

3. Derrien, M.; van Passel, M.W.; van de Bovenkamp, J.H.; Schipper, R.G.; de Vos, W.M.; Dekker, J. Mucin-Bacterial Interactions in the Human Oral Cavity and Digestive Tract. Gut Microbes 2010, 1, 254-268. [CrossRef]

4. Gendler, S.J.; Spicer, A.P. Epithelial Mucin Genes. Annu. Rev. Physiol. 1995, 57, 607-634. [CrossRef]

5. Wagner, C.E.; Wheeler, K.M.; Ribbeck, K. Mucins and Their Role in Shaping the Functions of Mucus Barriers. Annu. Rev. Cell Dev. Biol. 2018, 34, 189-215. [CrossRef]

6. Pearson, J.P.; Chater, P.I.; Wilcox, M.D. The Properties of the Mucus Barrier, a Unique Gel—How Can Nanoparticles Cross It? Ther. Deliv. 2016, 7, 229-244. [CrossRef]

7. Bansil, R.; Turner, B.S. The Biology of Mucus: Composition, Synthesis and Organization. Adv. Drug Deliv. Rev. 2018, 124, 3-15. [CrossRef]

8. Martinez-Saez, N.; Peregrina, J.M.; Corzana, F. Principles of Mucin Structure: Implications for the Rational Design of Cancer Vaccines Derived from Muc1-Glycopeptides. Chem. Soc. Rev. 2017, 46, 7154-7175. [CrossRef]

9. Perez-Vilar, J.; Hill, R.L. The Structure and Assembly of Secreted Mucins. J. Biol. Chem. 1999, 274, 31751-31754. [CrossRef]

10. Dekker, J.; Rossen, J.W.; Büller, H.A.; Einerhand, A.W. The Muc Family: An Obituary. Trends Biochem. Sci. 2002, $27,126-131$. [CrossRef]

11. Dhanisha, S.S.; Guruvayoorappan, C.; Drishya, S.; Abeesh, P. Mucins: Structural Diversity, Biosynthesis, Its Role in Pathogenesis and as Possible Therapeutic Targets. Crit. Rev. Oncol. Hematol. 2018, 122, 98-122. [CrossRef]

12. Lang, T.; Klasson, S.; Larsson, E.; Johansson, M.E.; Hansson, G.C.; Samuelsson, T. Searching the Evolutionary Origin of Epithelial Mucus Protein Components-Mucins and Fcgbp. Mol. Biol. Evol. 2016, 33, 1921-1936. [CrossRef] [PubMed]

13. Noguera, M.E.; Jakoncic, J.; Ermacora, M.R. High-Resolution Structure of Intramolecularly Proteolyzed Human Mucin-1 Sea Domain. Biochim. Biophys. Acta Proteins Proteom. 2020, 1868, 140361. [CrossRef] [PubMed]

14. Appella, E.; Weber, I.T.; Blasi, F. Structure and Function of Epidermal Growth Factor-Like Regions in Proteins. FEBS Lett. 1988, 231, 1-4. [CrossRef]

15. Ciccarelli, F.D.; Doerks, T.; Bork, P. Amop, a Protein Module Alternatively Spliced in Cancer Cells. Trends Biochem. Sci. 2002, 27, 113-115. [CrossRef]

16. Xu, D.; Pavlidis, P.; Thamadilok, S.; Redwood, E.; Fox, S.; Blekhman, R.; Ruhl, S.; Gokcumen, O. Recent Evolution of the Salivary Mucin Muc7. Sci. Rep. 2016, 6, 31791. [CrossRef] [PubMed]

17. Javitt, G.; Khmelnitsky, L.; Albert, L.; Bigman, L.S.; Elad, N.; Morgenstern, D.; Ilani, T.; Levy, Y.; Diskin, R.; Fass, D. Assembly Mechanism of Mucin and Von Willebrand Factor Polymers. Cell 2020, 183, 717-729.e16. [CrossRef]

18. Van Klinken, B.J.; Dekker, J.; Buller, H.A.; Einerhand, A.W. Mucin Gene Structure and Expression: Protection Vs. Adhesion. Am. J. Physiol. 1995, 269 Pt 1, G613-G627. [CrossRef]

19. Sicard, J.F.; le Bihan, G.; Vogeleer, P.; Jacques, M.; Harel, J. Interactions of Intestinal Bacteria with Components of the Intestinal Mucus. Front. Cell. Infect. Microbiol. 2017, 7, 387. [CrossRef]

20. Podolsky, D.K. Inflammatory Bowel Disease. N. Engl. J. Med. 1991, 325, 928-937. [CrossRef]

21. Guan, Q. A Comprehensive Review and Update on the Pathogenesis of Inflammatory Bowel Disease. J. Immunol. Res. 2019, 2019, 7247238. [CrossRef]

22. Roda, G.; Chien Ng, S.; Kotze, P.G.; Argollo, M.; Panaccione, R.; Spinelli, A.; Kaser, A.; Peyrin-Biroulet, L.; Danese, S. Crohn's Disease. Nat. Rev. Dis. Primers 2020, 6, 22. [CrossRef] [PubMed]

23. Jairath, V.; Feagan, B.G. Global Burden of Inflammatory Bowel Disease. Lancet Gastroenterol. Hepatol. 2020, 5, 2-3. [CrossRef]

24. Matijasic, M.; Mestrovic, T.; Peric, M.; Paljetak, H.C.; Panek, M.; Bender, D.V.; Kelecic, D.L.; Krznaric, Z.; Verbanac, D. Modulating Composition and Metabolic Activity of the Gut Microbiota in Ibd Patients. Int. J. Mol. Sci. 2016, 17, 578. [CrossRef]

25. Tytgat, K.M.; Opdam, F.J.; Einerhand, A.W.; Buller, H.A.; Dekker, J. Muc2 Is the Prominent Colonic Mucin Expressed in Ulcerative Colitis. Gut 1996, 38, 554-563. [CrossRef]

26. Pullan, R.D.; Thomas, G.A.; Rhodes, M.; Newcombe, R.G.; Williams, G.T.; Allen, A.; Rhodes, J. Thickness of Adherent Mucus Gel on Colonic Mucosa in Humans and Its Relevance to Colitis. Gut 1994, 35, 353-359. [CrossRef] [PubMed]

27. Moher, D.; Liberati, A.; Tetzlaff, J.; Altman, D.G.; Prisma Group. Preferred Reporting Items for Systematic Reviews and Meta-Analyses: The Prisma Statement. BMJ 2009, 339, b2535. [CrossRef]

28. Dorofeyev, A.E.; Vasilenko, I.V.; Rassokhina, O.A.; Kondratiuk, R.B. Mucosal Barrier in Ulcerative Colitis and Crohn's Disease. Gastroenterol. Res. Pract. 2013, 2013, 431231. [CrossRef]

29. Hensel, K.O.; Boland, V.; Postberg, J.; Zilbaur, M.; Heuschkel, R.; Vogel, S.; Gödde, D.; Wirth, S.; Jenke, A.C. Differential Expression of Mucosal Trefoil Factors and Mucins in Pediatric Inflammatory Bowel Diseases. Sci. Rep. 2014, 4, 7343. [CrossRef]

30. Swallow, D.M.; Vinall, L.E.; Gum, J.R.; Kim, Y.S.; Yang, H.; Rotter, J.I.; Mirza, M.; Lee, J.C.; Lennard-Jones, J.E. Ulcerative Colitis Is Not Associated with Differences in Muc2 Mucin Allele Length. J. Med. Genet. 1999, 36, 859-860.

31. Kyo, K.; Parkes, M.; Takei, Y.; Nishimori, H.; Vyas, P.; Satsangi, J.; Simmons, J.; Nagawa, H.; Baba, S.; Jewell, D.; et al. Association of Ulcerative Colitis with Rare Vntr Alleles of the Human Intestinal Mucin Gene, Muc3. Hum. Mol. Genet. 1999, 8, 307-311. [CrossRef] [PubMed] 
32. Weiss, A.A.; Babyatsky, M.W.; Ogata, S.; Chen, A.; Itzkowitz, S.H. Expression of Muc2 and Muc3 Mrna in Human Normal, Malignant, and Inflammatory Intestinal Tissues. J. Histochem. Cytochem. 1996, 44, 1161-1166. [CrossRef]

33. Tytgat, K.M.; van der Wal, J.W.; Einerhand, A.W.; Buller, H.A.; Dekker, J. Quantitative Analysis of Muc2 Synthesis in Ulcerative Colitis. Biochem. Biophys. Res. Commun. 1996, 224, 397-405. [CrossRef] [PubMed]

34. Hinoda, Y.; Akashi, H.; Suwa, T.; Itoh, F.; Adachi, M.; Endo, T.; Satoh, M.; Xing, P.X.; Imai, K. Immunohistochemical Detection of Muc2 Mucin Core Protein in Ulcerative Colitis. J. Clin. Lab. Anal. 1998, 12, 150-153. [CrossRef]

35. Van Klinken, B.J.; van der Wal, J.W.; Einerhand, A.W.; Buller, H.A.; Dekker, J. Sulphation and Secretion of the Predominant Secretory Human Colonic Mucin Muc2 in Ulcerative Colitis. Gut 1999, 44, 387-393. [CrossRef] [PubMed]

36. Hanski, C.; Born, M.; Foss, H.D.; Marowski, B.; Mansmann, U.; Arasteh, K.; Bachler, B.; Papenfuss, M.; Niedobitek, F. Defective Post-Transcriptional Processing of Muc2 Mucin in Ulcerative Colitis and in Crohn's Disease Increases Detectability of the Muc2 Protein Core. J. Pathol. 1999, 188, 304-311. [CrossRef]

37. Shaoul, R.; Okada, Y.; Cutz, E.; Marcon, M.A. Colonic Expression of Muc2, Muc5ac, and Tff1 in Inflammatory Bowel Disease in Children. J. Pediatr. Gastroenterol. Nutr. 2004, 38, 488-493. [CrossRef]

38. Longman, R.J.; Poulsom, R.; Corfield, A.P.; Warren, B.F.; Wright, N.A.; Thomas, M.G. Alterations in the Composition of the Supramucosal Defense Barrier in Relation to Disease Severity of Ulcerative Colitis. J. Histochem. Cytochem. 2006, 54, 1335-1348. [CrossRef]

39. Moehle, C.; Ackermann, N.; Langmann, T.; Aslanidis, C.; Kel, A.; Kel-Margoulis, O.; Schmitz-Madry, A.; Zahn, A.; Stremmel, W.; Schmitz, G. Aberrant Intestinal Expression and Allelic Variants of Mucin Genes Associated with Inflammatory Bowel Disease. J. Mol. Med. 2006, 84, 1055-1066. [CrossRef]

40. Furr, A.E.; Ranganathan, S.; Finn, O.J. Aberrant Expression of Muc1 Mucin in Pediatric Inflammatory Bowel Disease. Pediatr Dev. Pathol. 2010, 13, 24-31. [CrossRef]

41. Larsson, J.M.; Karlsson, H.; Crespo, J.G.; Johansson, M.E.; Eklund, L.; Sjovall, H.; Hansson, C.G. Altered O-Glycosylation Profile of Muc2 Mucin Occurs in Active Ulcerative Colitis and Is Associated with Increased Inflammation. Inflamm. Bowel Dis. 2011, 17, 2299-2307. [CrossRef] [PubMed]

42. Kini, A.T.; Thangaraj, K.R.; Simon, E.; Shivappagowdar, A.; Thiagarajan, D.; Abbas, S.; Ramachandran, A.; Venkatraman, A. Aberrant Niche Signaling in the Etiopathogenesis of Ulcerative Colitis. Inflamm. Bowel Dis. 2015, 21, 549-2561. [CrossRef]

43. Yamamoto-Furusho, J.K.; Ascano-Gutierrez, I.; Furuzawa-Carballeda, J.; Fonseca-Camarillo, G. Differential Expression of Muc12, Muc16, and Muc20 in Patients with Active and Remission Ulcerative Colitis. Mediat. Inflamm. 2015, 2015, 659018. [CrossRef]

44. Alipour, M.; Zaidi, D.; Valcheva, R.; Jovel, J.; Martinez, I.; Sergi, C.; Walter, J.; Mason, A.L.; Wong, G.K.; Dieleman, L.A.; et al. Mucosal Barrier Depletion and Loss of Bacterial Diversity Are Primary Abnormalities in Paediatric Ulcerative Colitis. J. Crohn's Colitis 2016, 10, 462-471. [CrossRef] [PubMed]

45. van der Post, S.; Jabbar, K.S.; Birchenough, G.; Arike, L.; Akhtar, N.; Sjovall, H.; Johansson, M.E.V.; Hansson, G.C. Structural Weakening of the Colonic Mucus Barrier Is an Early Event in Ulcerative Colitis Pathogenesis. Gut 2019, 68, 2142-2151. [CrossRef] [PubMed]

46. Gersemann, M.; Becker, S.; Kübler, I.; Koslowski, M.; Wang, G.; Herrlinger, K.R.; Griger, J.; Fritz, P.; Fellermann, K.; Schwab, M.; et al. Differences in Goblet cell Differentiation between Crohn's Disease and Ulcerative Colitis. Differentiation 2009, 77, 84-94. [CrossRef] [PubMed]

47. Senapati, S.; Ho, S.B.; Sharma, P.; Das, S.; Chakraborty, S.; Kaur, S.; Niehans, G.; Batra, S.K. Expression of Intestinal MUC17 Membrane-bound Mucin in Inflammatory and Neoplastic Diseases of the Colon. J. Clin. Pathol. 2010, 63, 702-707. [CrossRef] [PubMed]

48. Cumpston, M.; Li, T.; Page, M.J.; Chandler, J.; Welch, V.A.; Higgins, J.P.; Thomas, J. Updated Guidance for Trusted Systematic Reviews: A New Edition of the Cochrane Handbook for Systematic Reviews of Interventions. Cochrane Database Syst. Rev. 2019, 10, ED000142. [CrossRef]

49. Grondin, J.A.; Kwon, Y.H.; Far, P.M.; Haq, S.; Khan, W.I. Mucins in Intestinal Mucosal Defense and Inflammation: Learning from Clinical and Experimental Studies. Front. Immunol. 2020, 11, 2054. [CrossRef]

50. Parikh, K.; Antanaviciute, A.; Fawkner-Corbett, D.; Jagielowicz, M.; Aulicino, A.; Lagerholm, C.; Davis, S.; Kinchen, J.; Chen, H.H.; Alham, N.K.; et al. Colonic Epithelial Cell Diversity in Health and Inflammatory Bowel Disease. Nature 2019, $567,49-55$. [CrossRef]

51. Forgue-Lafitte, M.E.; Fabiani, B.; Levy, P.P.; Maurin, N.; Flejou, J.F.; Bara, J. Abnormal Expression of M1/Muc5ac Mucin in Distal Colon of Patients with Diverticulitis, Ulcerative Colitis and Cancer. Int. J. Cancer 2007, 121, 1543-1549. [CrossRef]

52. Rehman, S.; Grigoryeva, L.S.; Richardson, K.H.; Corsini, P.; White, R.C.; Shaw, R.; Portlock, T.J.; Dorgan, B.; Zanjani, Z.S.; Fornili, A.; et al. Structure and Functional Analysis of the Legionella Pneumophila Chitinase Chia Reveals a Novel Mechanism of Metal-Dependent Mucin Degradation. PLoS Pathog. 2020, 16, e1008342. [CrossRef]

53. Wong, E.; Vaaje-Kolstad, G.; Ghosh, A.; Hurtado-Guerrero, R.; Konarev, P.V.; Ibrahim, A.F.; Svergun, D.I.; Eijsink, V.G.; Chatterjee, N.S.; van Aalten, D.M. The Vibrio Cholerae Colonization Factor Gbpa Possesses a Modular Structure That Governs Binding to Different Host Surfaces. PLoS Pathog. 2012, 8, e1002373. [CrossRef]

54. Atanasova, K.R.; Reznikov, L.R. Strategies for measuring airway mucus and mucins. Respir. Res. 2019, 20, 261. [CrossRef] 